\title{
Review Article \\ Recent Advances in Facile Synthesis of Bimetallic Nanostructures: An Overview
}

\author{
Arash Dehghan Banadaki and Amir Kajbafvala \\ Department of Materials Science and Engineering, North Carolina State University, 911 Partners Way, \\ Engineering Building I, Raleigh, NC 27695-7907, USA
}

Correspondence should be addressed to Amir Kajbafvala; akajbaf@ncsu.edu

Received 7 March 2014; Accepted 14 April 2014; Published 14 July 2014

Academic Editor: Karthik S. Pillai

Copyright (C) 2014 A. Dehghan Banadaki and A. Kajbafvala. This is an open access article distributed under the Creative Commons Attribution License, which permits unrestricted use, distribution, and reproduction in any medium, provided the original work is properly cited.

\begin{abstract}
Nobel metal nanomaterials with interesting physical and chemical properties are ideal building blocks for engineering and tailoring nanoscale structures for specific technological applications. Bimetallic nanomaterials consisting of magnetic metals and noble metals have attracted much interest for their promising potentials in many fields including magnetic sensors, catalysts, optical detection, and biomedical applications. Particularly, effective control of the size, shape, architecture, and compositional microstructure of metal nanomaterials plays an important role in enhancing their functionality and application potentials, for example, in fuel cells, optical and biomedical sensing. This paper focuses on recent advances in controllable synthesis of bimetallic nanostructured materials. Recent contributions in controllable synthesis of bimetallic nanomaterials with different architectures including nanoparticles, nanowires, nanosheets, or nanotubes and their assemblies are presented in this paper. A wide range of facile synthesis methods are covered herein with high emphasis on wet chemical methods owing to their facility of use, efficacy, and smaller environmental footprint.
\end{abstract}

\section{Introduction}

Nanoscience and nanotechnology have grown at an enormous rate in the last three decades, and recent advances in nanostructured materials have opened up new opportunities for diverse applications in electronics, catalysis, energy, materials chemistry, and even biology. Materials in the nanometer-size regime often exhibit properties distinct from their bulk counterparts, in part because nanosized clusters have electronic structures that have a high density of states, but not yet continuous bands [1-6]. Facile synthesis in designing nanostructured materials has been a driving force for the development of new methodologies for several decades. Indeed, this has led scientists' interest to the development of versatile and generalized synthetic methods readily adaptable for the preparation of a variety of nanostructured materials [7]. Nanostructured materials have been prepared by a variety of synthetic methods, including microwave, ultrasonic, sonochemistry, sol-gel, chemical vapor deposition, and chemical precipitation. One could claim that selecting an appropriate synthesis route ultimately determines the success or failure of nanostructured materials, as physical properties and applications of nanostructured materials are heavily dependent upon the preparation method [8-35].

Metallic materials play an undeniable role in the modern human life $[36,37]$. From architecture, transportation equipment, electronic technology, information science, and technology to biomedical applications, metallic materials are all indispensable constituents [38-40]. Compared to their bulk counterparts, possessing high mechanical strength, good malleability, and electric-magnetic properties, metal nanomaterials exhibit particular physical and chemical characteristics because of their small-size effect, surface area, and quantum-size effect and have potential applications in the fields of catalysis, magnetic recording, sensing, medical diagnosis, and so forth [41, 42]. For example, nanomaterials like $\mathrm{Cu}, \mathrm{Ag}$, and $\mathrm{Au}$ have surface plasmon in the visible light regime of the spectrum which can be used as biosensor imaging and optoelectronic devices $[43,44]$. Some nanomaterials, such as $\mathrm{Pt}$ and $\mathrm{Pd}$, as well as $\mathrm{Ag}$ and $\mathrm{Au}$, have 
outstanding catalytic activity. The transition metals, such as $\mathrm{Fe}, \mathrm{Co}$, and $\mathrm{Ni}$, are ferromagnetic elements which have been widely used in different magnetic and spintronic devices [45]. Bulk Au is a nonmagnetic yellow metal; however, $10 \mathrm{~nm} \mathrm{Au}$ nanoparticles appear red because they can absorb green light; 2-3 nm Au particles exhibit considerable magnetism; smaller $\mathrm{Au}$ nanoparticles can even turn into insulators [46, 47]. Although bulk $\mathrm{Au}$ is very unreactive for low-temperature carbon monoxide (CO) oxidation, nanoscale Au particles are chemically active for this reaction and it has been proven that Au clusters in the range of $3.5 \mathrm{~nm}$ exhibit the maximum reactivity $[48,49]$. Above examples indicate why, controllable synthesis of metal nanostructured materials has attracted much attention over the past two decades [50-53].

Bimetallic nanomaterials, composed of two distinct metal elements, have a certain mixing pattern or chemistry sequence and geometry architecture and perform specific functions $[54,55]$. Their performance often surpasses the enhancement of the properties associated with their single counterparts and exhibits many interesting and useful properties with broadened application fields often explained by synergistic effects of nanomaterials [56-59]. By changing their components and morphologies, their relevant physical, electrical, or chemical performances can be successfully modified $[60,61]$. Discovering the nano-/microstructure nature of physiochemical properties in the bimetallic nanomaterials has become the main focus of many researchers [62-74].

The structures of bimetallic nanomaterials are complicated and can take multiple forms. According to the mixing pattern of two different metals, three main types of structures can be identified for bimetallic nanomaterials, that is, core/shell, heterostructure or intermetallic, and alloyed structures $[46,75]$. In the formation process of core/shell structures, often one type of metal ions is reduced first and forms an inner core, while the other metal grows as a shell surrounding the nucleated core. However, under proper conditions, individual nucleation and growth of two kinds of metal atoms can occur. If they share a mixed interface during the growth process, heterostructure forms. Intermetallics and alloys belong to another group entirely different from core/shell or heterostructure bimetallic nanomaterials. They are both a homogeneous mixture of two metals where often metal-metal bonds are dominant structure of the products. The difference between these two groups can be reflected in the powder X-ray diffraction (PXRD) patterns. For core/shell or heterostructure compounds, the characteristic diffraction peaks of two kinds of metals can be observed together, while for intermetallics and alloys, the characteristic peaks of individual metals disappear and new Bragg reflections can be observed, indicating that new compounds are created. The distribution of two distinct metal atoms determines the structure of the product. In general, alloys have random atomic orders, while intermetallics have long-range atomic orders.

Although many methods have been developed for the preparation of monometallic nanomaterials (especially for $\mathrm{Ag}, \mathrm{Au}, \mathrm{Pd}, \mathrm{Pt}$, etc.) $[76,77]$, controllable synthesis of bimetallic nanomaterials is much more complicated $[78,79]$. The synthesis of bimetallic compounds can be carried out in the solid, gaseous, or solution state. Bimetallic compounds are traditionally obtained using metallurgical techniques which melts two kinds of bulk metals under proper conditions [80]. This solid state method requires high-temperature heating and annealing for long periods of time, and it is difficult to obtain nanocrystalline bimetallic compounds with high surface areas which are urgently needed in various applied fields such as energy, environment, and catalysis [81]. The solution state method is more powerful and versatile and has been the preferred method by many researchers lately. In a solution-based synthetic system, the nucleation and growth process of bimetallic nanomaterials can be easily controlled by adjusting the reaction parameters including the concentration of reactants, the mole ratio between precursors and surfactants, and the reaction temperature and time, which has been confirmed during the preparation of monometallic nanomaterials. Nevertheless it is not an easy task to synchronously control the nucleation and growth of two distinct metals due to their different thermodynamic and kinetic characteristics under the same reaction conditions. In recent years, researchers have made great efforts in controllable synthesis of bimetallic nanomaterials. In the following section, we present a review on facile, green, and low-cost methods for synthesis of bimetallic nanomaterials.

\section{Discussion}

It has been observed that development of the catalysts in the form of zero-dimensional (0D) nanostructures (nanoparticles) or one-dimensional (1D) nanostructures (nanowires/nanotubes) increases the efficiency of the materials and lowers the costs of production. Thanks to their higher surface area, nanoparticles exhibit higher catalytic activity but show less stability over the time mainly due to their tendency to agglomerate forming larger particles. 1D nanostructures however are less prone to instability over multiple use since the agglomeration is less likely to happen in 1D structures [82-86]. Furthermore they show better carbon corrosion resistance particularly for the carbon supported systems. Bimetallic structures or alloy metal nanocrystals usually have better catalyst performance than monometals owing to the synergistic effect of both metals $[87,88]$. The following parts of this paper provide a summary of the latest facile synthesis techniques employed in developing bimetallic nanostructures with different morphologies (including 0D, $1 \mathrm{D}$, etc.). The organization of the sections of this paper is based upon the importance of certain metals and amount of attention directed toward certain combinations by the leading research community.

2.1. PdPt Nanostructures. Due to their relatively high energy density and convenient form factor, direct alcohol fuel cells (DAFCs) have attracted considerable attention as power sources. Pt and Pd owing to their high electrocatalytic activities are considered the most efficient noble-metal catalysts for DAFCS. High production costs and low resources for noble-metal materials are the main hurdle in developing efficient DAFCS. The following section summarizes 

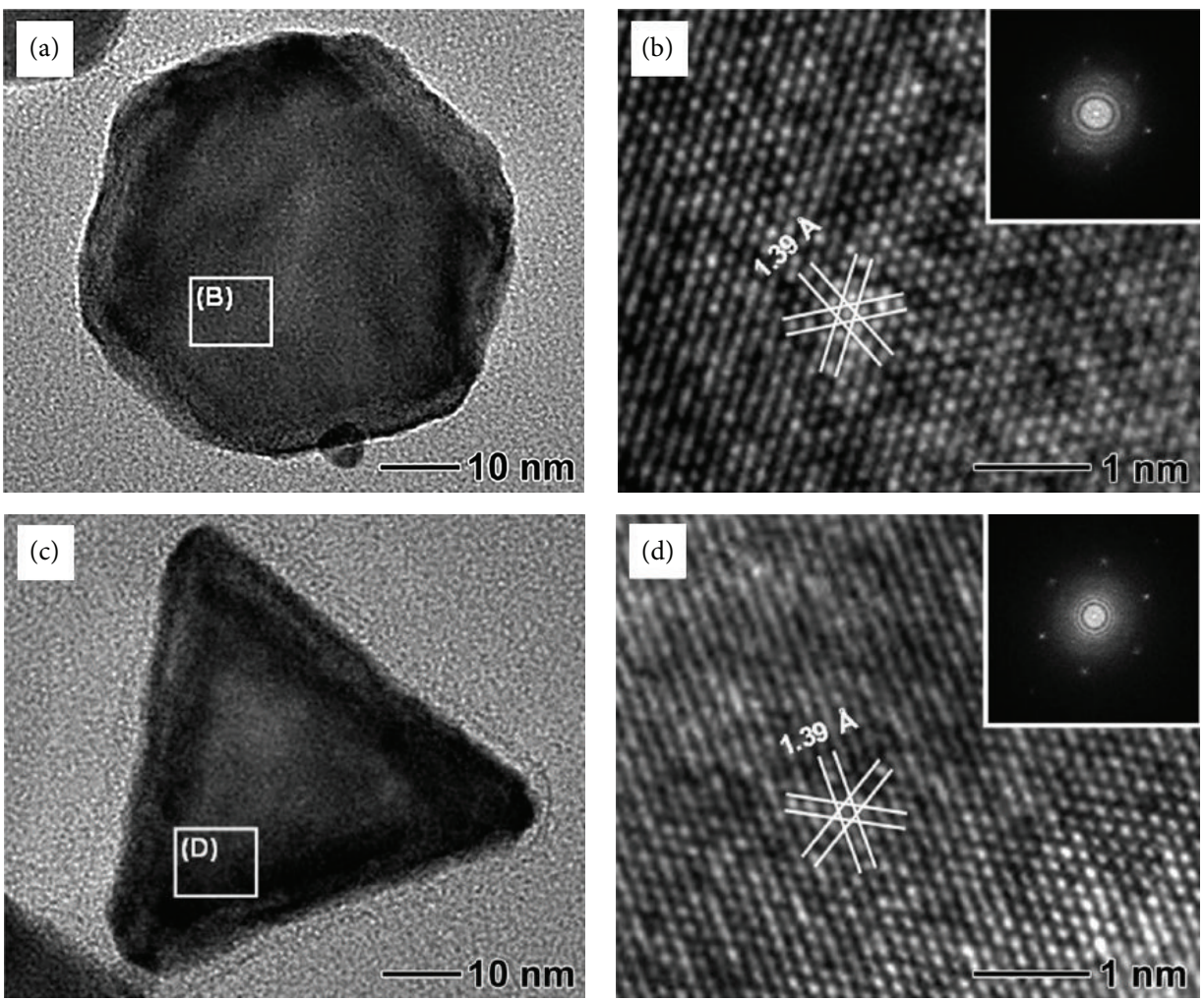

FIGURE 1: High resolution transmission electron microscope (HRTEM) images taken along a direction perpendicular to the flat top faces of (a, b) hexagonal and (c, d) triangular PdPt core/shell nanoplates. (Adapted with permission from [89]. Copyright 2008 American Chemical Society.)

the latest research devoted to development of facile synthesis techniques for producing the PtPd nanostructures leading to improved catalytic activity, higher stability, and lower costs. The majority of the researchers in the recent years seem to prefer the wet chemical reduction procedure for synthesis of nanostructure; hence, we start with this method and finish with the highlights of other methods.

2.1.1. Wet Chemical Reduction. It has been observed that Pt monolayer supported on a Pd (111) surface shows an improved activity for oxygen reduction reaction (ORR) relative to pure Pt (111) surface. Lim et al. [89] used an epitaxial growth technique to grow thin Pt layers on triangular or hexagonally shaped $\mathrm{Pd}$ nanoplates (Figure 1). $\mathrm{Na}_{2} \mathrm{PdCl}_{4}$ is first reduced using poly-N-vinyl-2-pyrrolidone (PVP) and forms the $\mathrm{Pd}$ nanoplates which serve as seeds for Pt atoms. Next, Pt atoms are formed by reducing the $\mathrm{H}_{2} \mathrm{PdCl}_{6}$ using citric acid. In this synthesis approach, small lattice mismatch $(0.77 \%)$ between $\mathrm{Pt}$ and $\mathrm{Pd}$ as well as mild reduction speed of citric acid are identified as the key parameters in achieving the growth of $\mathrm{Pt}$ shells on Pd nanoplates.

Later in an effort to further increase the unit surface area of the Pt-based electrocatalysts and reduce the Pt load hence cost of the fuel cells, Lim et al. proposed a method for synthesis of PdPt bimetallic nanodendrites consisting of a dense array of Pt branches on Pd nanocrystals (uniform octahedrals produced by reducing $\mathrm{Na}_{2} \mathrm{PdCl}_{4}$ with $\mathrm{L}$-ascorbic acid in an aqueous solution) $[90,91]$. They used L-ascorbic acid to reduce the $\mathrm{K}_{2} \mathrm{PtCl}_{4}$ in presence of uniform Pd nanocrystal seeds in aqueous solution (Figure 2). Using their simple method of synthesis, they were able to produce substantially high surface areas and oxygen reduction reactivity (ORR). Their product showed two and a half times more activity on the basis of equivalent Pt mass for the ORR than the stateof-the-art Pt/C catalyst and five times more activity than the first-generation supportless Pt-black catalyst.

In 2010 and for the first time, Guo et al. [92] proposed a wet chemical approach for the synthesis of highquality three-dimensional (3D) Pt-on-Pd bimetallic nanodendrites supported on graphene nanosheets (TP-BNGN) with porous texture, considerable electrochemically active area, and much higher (up to 4 times) electrocatalytic activity toward methanol oxidation than the platinum black (PB) and commercial E-TEK Pt/C catalysts. PVP-functionalized graphene nanosheets were used to load small Pd nanoparticles for producing graphene/Pd nanoparticle hybrids via a simple and surfactantless route at room temperature. They used the ascorbic acid for reducing the $\mathrm{K}_{2} \mathrm{PtCl}_{4}$ in an aqueous solution for direct growth of the $\mathrm{Pt}$ on $\mathrm{Pd}$ seeds. One of the main limitations of the Pt-nanoparticle based catalysts is the lack of durability in the strongly acidic medium. Mazumder et al. [93] investigated the performance of $\mathrm{Pd} / \mathrm{FePt}$ core/shell structure in strongly acidic medium of $0.1 \mathrm{~mol} \mathrm{HClO}_{4}$. They also showed that the catalysis of these nanoparticles is a function of FePt shell thickness. Their product showed much higher durability while exposed to $\mathrm{HCLO}_{4}$. They compare 

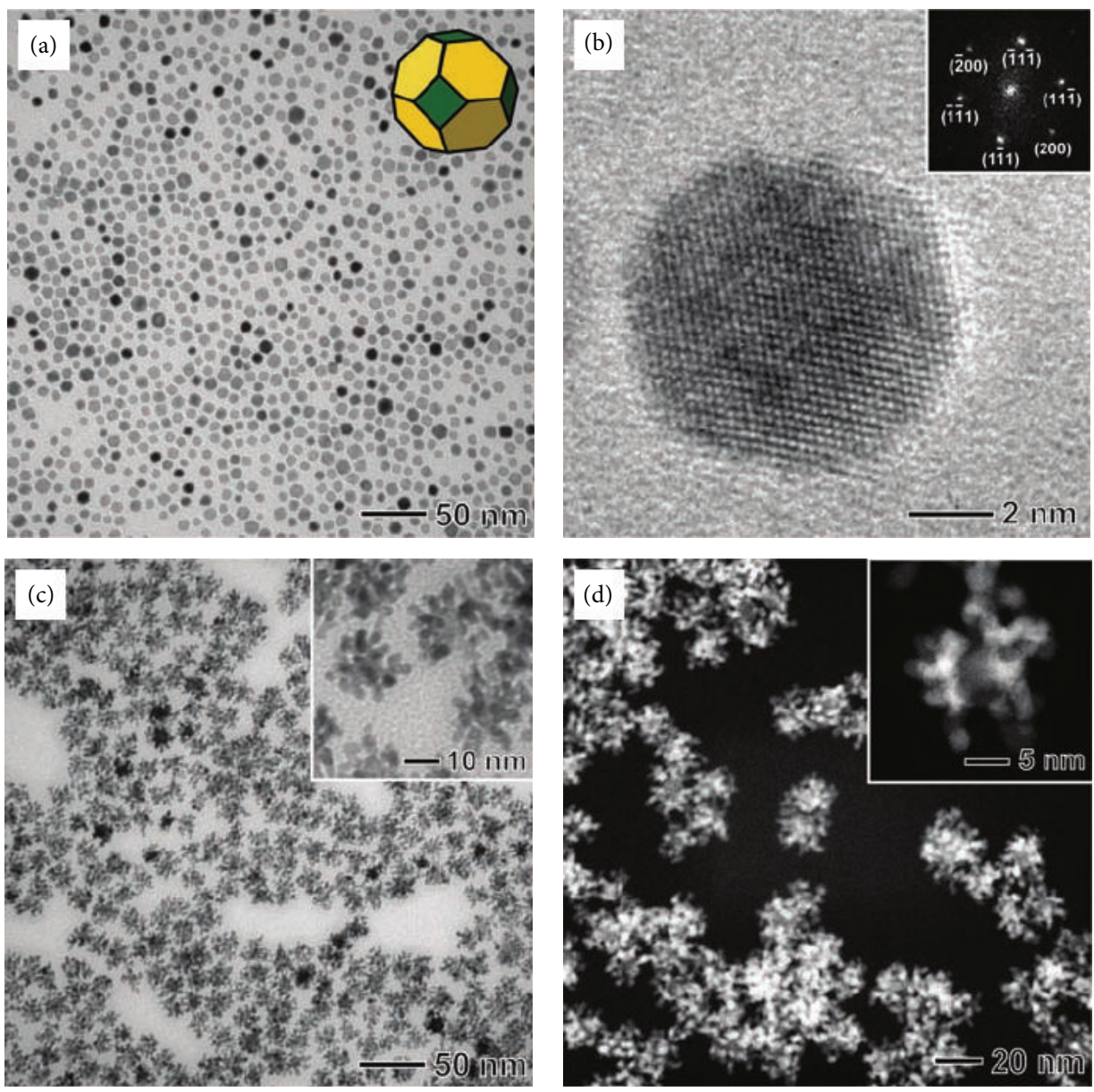

Figure 2: (a) TEM image of truncated octahedral Pd nanocrystals. (b) HRTEM image of a single truncated octahedron of Pd recorded along the [011] zone axis. (c) TEM image of PdPt nanodendrites. (d) High angle annular dark field (HAADF) STEM image of PdPt nanodendrites. (Adopted with permission from [90]. Copyright 2009 American Association for the Advancement of Science.)

the ORR of their product with a commercial Pt catalyst (BASF) and show approximately 12 times higher performance compared to the commercial counterpart. Wang et al. $[94,95]$ proposed a facile and economical approach to improve the activity and reduce the Pt consumption of the electrocatalysts by galvanic displacement reaction between $\mathrm{PdCu} / \mathrm{C}$ and the $\mathrm{PtCl}_{6}{ }^{2-}$ to deposit the Pt atoms on the template. Liu et al. [96] proposed a more sophisticated yet facile procedure for synthesis of PtPd nanoparticles. Their method is based on coreduction of $\operatorname{Pd}(\mathrm{acac})_{2}$ (acac = acetylacetonate $)$ and $\mathrm{Pt}(\mathrm{acac})_{2}$ with morpholine borane in oleylamine at 90 and $180^{\circ} \mathrm{C}$. Based on the operating temperature, they were able to control the relative proportion of the Pd to Pt. The prepared nanoparticles exhibit both durability and activity in optimum proportion of Pd to Pt. Long et al. [97] used a slightly different approach by employing $\mathrm{AgNO}_{3}$ as the metallic salt. In their proposed method, the simultaneous reduction of the mixture of PtPd precursors by ethylene glycol occurred in the presence of PVP and $\mathrm{AgNO}_{3}$ at $160^{\circ} \mathrm{C}$. They suggested that the thickness of the Pd nanoshell can be controlled by the quantity of the $\mathrm{Na}_{2} \mathrm{PdCl}_{4}$ precursor. They also observed that the morphologies of the PtPd core/shell nanoparticles depend on the crystal orientation of these nanoparticles.
For certain applications, such as optical sensing and localized surface plasmon resonance, nanoparticles with concave structure have received much attention. Zhang et al. $[98,99]$ used a simple galvanic replacement reaction between $\mathrm{PtCl}_{6}{ }^{2-}$ ions and Pd nanocrystals to fabricate PdPt based bimetallic concave nanocrystals with different shapes. They utilized combination of the PVP and $\mathrm{KBr}$ as the reducing medium and utilized the preferential adsorption of $\mathrm{Br}^{-}$ions only on the 111 facets of Pd and also reaction time to various morphologies (Figure 3). Their product showed four times higher catalytic activity compared to commercial Pt/C. Wu et al. [100] recently devised a very fast procedure for preparing macroscopic free-standing Pd and PdPt 2D nanomembranes. They used the aqueous solution of $\mathrm{PdCl}_{2}$ and $\mathrm{Na}_{3} \mathrm{CA}$ as the base at boiling temperature and $\mathrm{NH}_{2} \mathrm{OH} \cdot \mathrm{HCl}$ as the reducing agent and produced the nanomembranes in a fast self-assembly at water-air interface as fast as 15 minutes. Their best performing product $\left(\mathrm{Pd}_{3} 3 \mathrm{Pt}_{67}-\mathrm{FNMs}\right)$ showed 4.4 times higher catalytic performance than commercial Pt black. In 2013, Huang et al. [101] used a facile wet chemical strategy to synthesize PdPt bimetallic nanotubes by self-assembly of Pt and $\mathrm{Pd}$ on Te nanowires at room temperature. Te nanowires were used as both reducing agent and sacrificial template 

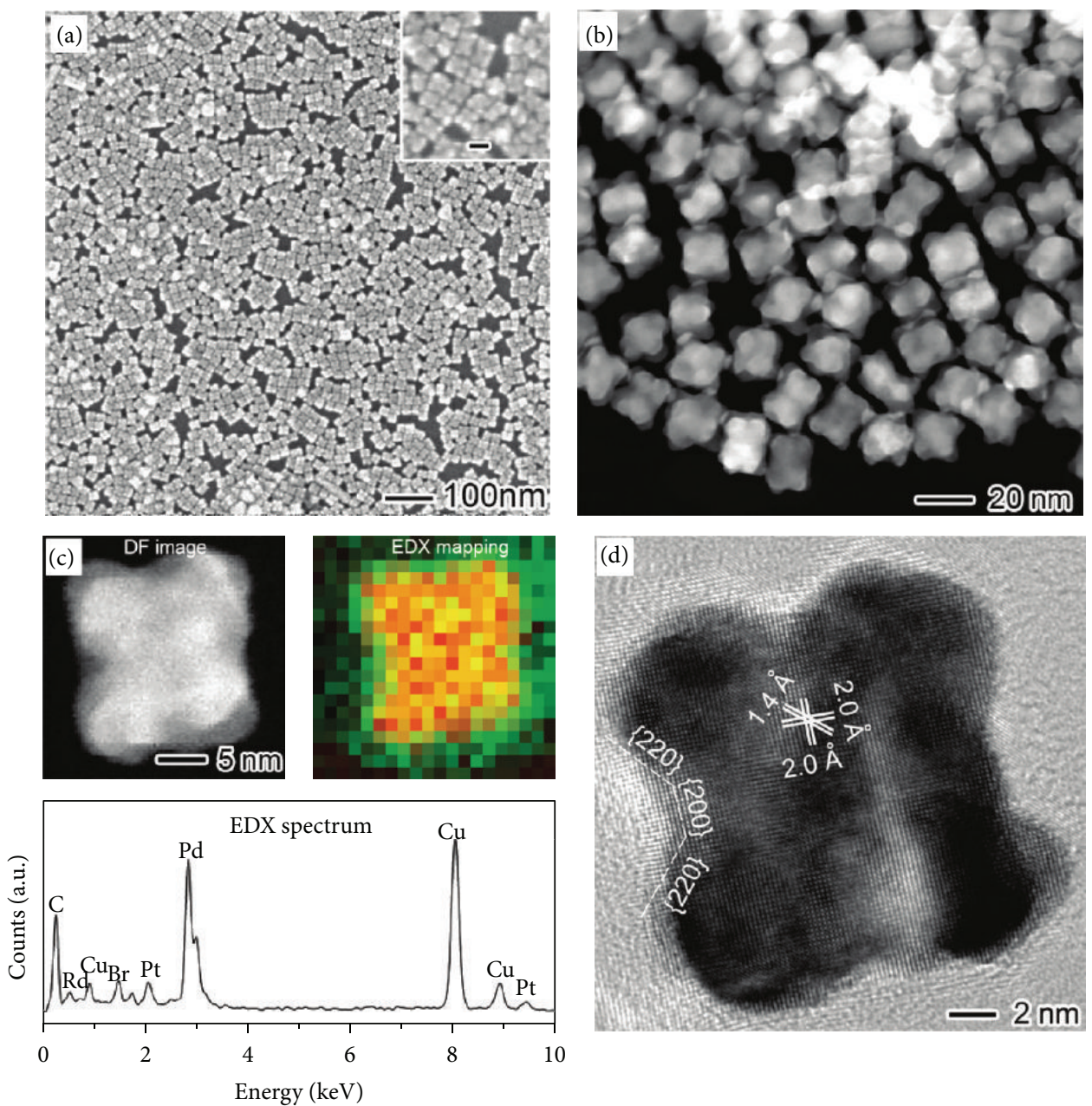

Energy $(\mathrm{keV})$

Figure 3: The morphology, structure, and composition of the PdPt concave nanocubes that were prepared using the standard procedure. (a) Scanning electron microscope (SEM) image, (b) HADDF-STEM image, (c) dark-field TEM and energy dispersive spectroscopy (EDS) mapping/analysis, and (d) HRTEM image. (Adopted with permission from [98]. Copyright 2011 American Chemical Society.)

for obtaining PdPt nanotubes in aqueous solution. They observed improved stability as well as superior catalytic activity due to the change in morphology of the nanostructures from zero- to one-dimensional structure. Table 1 summarizes the key components of wet chemical methods for synthesis of PdPt nanostructures.

2.1.2. Other Methods. Besides wet chemical reduction of precursor metals, other methods have been proposed for synthesis of PtPd nanoparticles [102-106]. Kobayashi et al. [103] reported a solid-solution alloy where Pd and Pt are homogeneously mixed at the atomic level using the process of hydrogen absorption/desorption (PHAD). Zhang et al. [104] produced three-dimensional PdPt core/shell nanostructures with controllable shape and composition by using a one-step microwave heating method. The optimum PdPt particles have a mass activity of 11 times higher than that of pure Pt. Similarly, Bo et al. [105] used microwave irradiation to prepare PtPd bimetallic alloy nanoparticles on onion shaped mesoporous carbon vesicle $(\mathrm{MCV})$ as a template in presence of ethylene glycol. More recently, Cao et al.
[106] used electrochemical deposition to consolidate the $\mathrm{PdPt}$ compound on a chitosan-grapheme hybrid $\left(\mathrm{C}_{\mathrm{s}}-\mathrm{G}_{\mathrm{s}}\right)$ modified glassy carbon electrode (GCE). Their proposed method involves the deposition of the PdPt in aqueous solution containing $0.5 \mathrm{mM}$ of $\mathrm{H}_{2} \mathrm{PtCl}_{6}$ and $0.5 \mathrm{mM} \mathrm{PdCl}$ for 200 seconds. The obtained product has been used as a biosensor to measure the cholesterol level in blood.

2.2. AuAg Nanostructures. AuAg nanoparticles are of great importance mainly due to their optical properties owing to their surface plasmon resonance (SPR). Smaller particles can strongly scatter the photon path, hence enhancing the electromagnetic field surrounding the particle. This phenomenon is the main motivation in achieving smaller AuAg nanoparticles with controlled morphologies. However, other properties of these particles, for example, catalytic activity with $\mathrm{CO}$, have been investigated and utilized for various purposes. AuAg nanoparticles (similar to other bimetallic nanoparticles) are prepared in two main categories: alloyed bimetallic nanostructures and core/shell nanoparticles [107]. The alloyed structures are prepared using three main processes, 


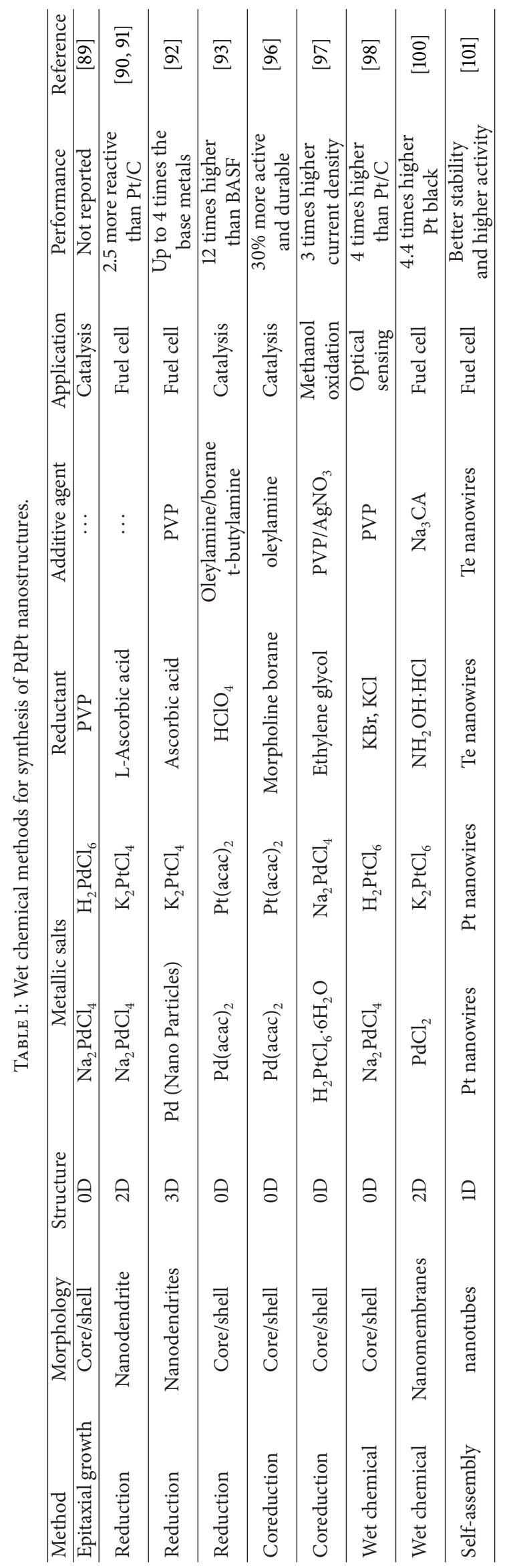


the simplest being the co-reduction of both monometallic nanoparticles with poor control on the shape and size. Second is often referred to as digestive ripening and involves refluxing a mixture of $\mathrm{Au}$ and $\mathrm{Ag}$ nanoparticles in 4-tertbutyltoluene for an extended period of time in the presence of dodecanethiol and argon. Finally, replacement reaction is another effective alloying procedure for preparing the $\mathrm{AuAg}$ nanoparticles. This method relies on the difference in standard electrode potential between Au and Ag. Core/shell structures however are prepared in two main categories, namely, seed mediated growth and replacement reaction. The former is the most commonly used method in preparing core/shell AuAg nanoparticles. The core particles are often prepared in a separate procedure and shell is being deposited later in the process. Core and shell atoms are interchangeable and the morphology of the product is dictated and can be controlled by the core particles. Replacement reaction can also be used to create core/shell nanostructures with Ag cores. This process can fabricate three different products (core/shell nanoparticles, hollow nanoparticles, and AgAu alloys) where the size and type of the product are strongly dictated by the synthesis conditions. The following section includes important milestones and latest developments in preparing the AuAg nanoparticles using the above methods. Similar to the previous section, we start with the wet chemical reduction methods as the method of choice for facile and green synthesis of nanoparticles and finish with other novel methods for this purpose.

2.2.1. Wet Chemical Reduction. In 2004, Selvakannan et al. [108] were the very first who devised a new ecofriendly synthesis method for fabricating the AuAg nanoparticles. Among many amino acids, they found that amino acid, tyrosine, is capable of reducing silver ions under alkaline conditions. They used tyrosine to reduce their aqueous silver sulfate solution and produce the Ag nanoparticles. They again used tyrosine along with the $\mathrm{Ag}$ nanoparticles and $\mathrm{HAuCl}_{4}$ to deposit Ag particles on Au. Later in 2006, Sakai and Alexandridis proposed poly(ethylene oxide)-poly(propylene oxide) (PEO-PPO) as the reducing agent for producing AuAg nanoparticles $[109,110]$. They found out that, based on the concentration of the reductants, they are able to control the core/shell structure of the product. Based on this observation, they were able to create different nanostructures all in single mixing (one-pot) procedure.

Chen et al. [111] and later Lee et al. [112] proposed a method for fabricating porous cubic shaped nanoparticles with controllable pores. Lee et al. used truncated Ag nanocubes produced in advance via a thermal annealing process. Then $\mathrm{HAuCl}_{4}$ is reduced in presence of PVP. The galvanic replacement reaction occurs with priority on $\{100\}$ planes and the amount of $\mathrm{HAuCl}_{4}$ is shown to control the amount of etching at the corner of cubes while the prepared nanoparticles can be utilized for drug delivery (Figure 4).

Liu et al. [113] used $\mathrm{NaBH}_{4}$ to reduce the $\mathrm{AuCl}_{4}{ }^{-}$and used $\mathrm{AgNO}_{3}$ as the precursor to produce $\mathrm{AuAg}$ nanoparticles. They used commercial silica/alumina as support for the deposition. They found out that the Ag particles obtained from the mentioned reduction process are highly uniform in size $(\sim 3 \mathrm{~nm})$ even in elevated temperatures and resist sintering. Their product showed up to 5 times better CO oxidation capability even better than $\mathrm{AU} / \mathrm{TiO}_{2}$. Among many chemical reduction methods, Philip in her paper proposed a unique and completely green procedure for synthesis of AuAg nanoparticles [114]. She proposed a mushroom extract (from Volvariella volvacea) as a reducing/stabilizing agent to be blended with $\mathrm{HAuCl}_{4}-3 \mathrm{H}_{2} \mathrm{O}$ and $\mathrm{AgNO}_{3}$. However the size distribution of the particles seemed to be unfavorably wide. Recently much attention has been directed toward proposing a fabrication procedure capable of generating nonsymmetric bimetallic particles (Figure 5). Xing et al. [115] proposed a new approach that reduces the symmetry of Au nanocores in an AuAg nanoparticle by limiting the availability of the free surface for deposition. In this case, eccentric polymer PANI (polyaniline) shells have been utilized to control the overgrowth of $\mathrm{Ag}^{+}$ions on $\mathrm{Au}$ nanorods.

Tokonami et al. [116] proposed a method for synthesis of $\mathrm{AuAg}$ nanoparticles by adding the $\mathrm{AgClO}_{4}$ into an aqueous dispersion of $\mathrm{Au}$ nanoparticles in room temperature. Netzer et al. [117] report a simple and straightforward method to fabricate AuAg bimetallic porous nanowires with superior surface enhanced Raman scattering activities. Their nanowires were obtained by dispersing the $\mathrm{Ag}$ nanowires in $\mathrm{HAuCl}_{4}$ at room temperature. Recently, Hong et al. [118] report a technique for producing ultrathin AuAg nanowires by using octadecylamine as both a solvent and a surfactant. The latest development in the field involves the use of a particular form of starch (i.e., degraded pueraria starch-DPS) as a reducing agent and capping agent reported by Xia et al. [119]. They used preprepared Ag nanoparticle seeds and mixed them with Au ions and DPS in an aqueous solution. The resulting bimetallic nanoparticles were observed to grow in DPS matrix as the capping and reducing agent. The proposed method yields spherically shaped nanoparticles with high catalytic activity (higher than AgAu monometallic nanoparticles) while being considerably facile and green. Table 2 summarizes the key components of wet chemical methods for synthesis of AuAg nanostructures.

2.2.2. Other Methods. Okazaki et al. [120, 121] proposed a considerably different approach for synthesizing nanoparticles. They used a sputtering technique to simultaneously deposit gold and silver particles in ionic liquids (ILs). The composition of nanoparticles is controlled by controlling the area and arrangement of the metals in the circular foils. They proposed a fan shape configuration in which the area of both of the elements can be controlled. The produced nanoparticles have uniformly sized spherical shapes ranging between 3 and $9 \mathrm{~nm}$. Gonzalez et al. used photochemical cleavage process to generate $\mathrm{AuAg}$ nanoparticles [122]. Depending on the type of surfactant being used, different structures were obtained, that is, core/shell structures and alloy nanoparticles. In their procedure, they used cetyltrimethylammonium chloride (CTAC) and sodium dodecyl sulfate (SDS) as surfactants and conventional metallic salts as reductants. Shang et al. [123] proposed a strategy that extends the use of polyelectrolyte multilayer (PEM) nanoreactors to generate bimetallic nanoparticles. Their procedure consists of loading 


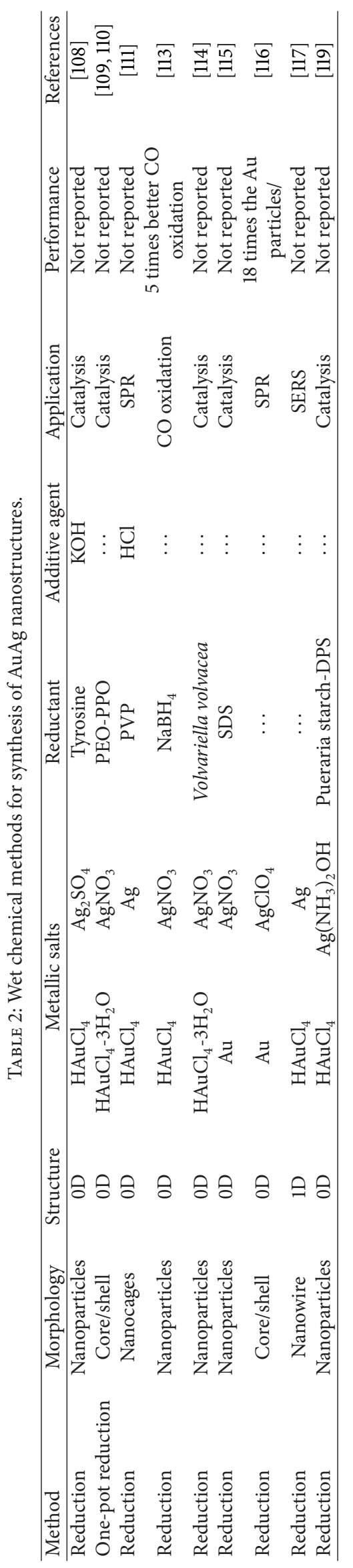



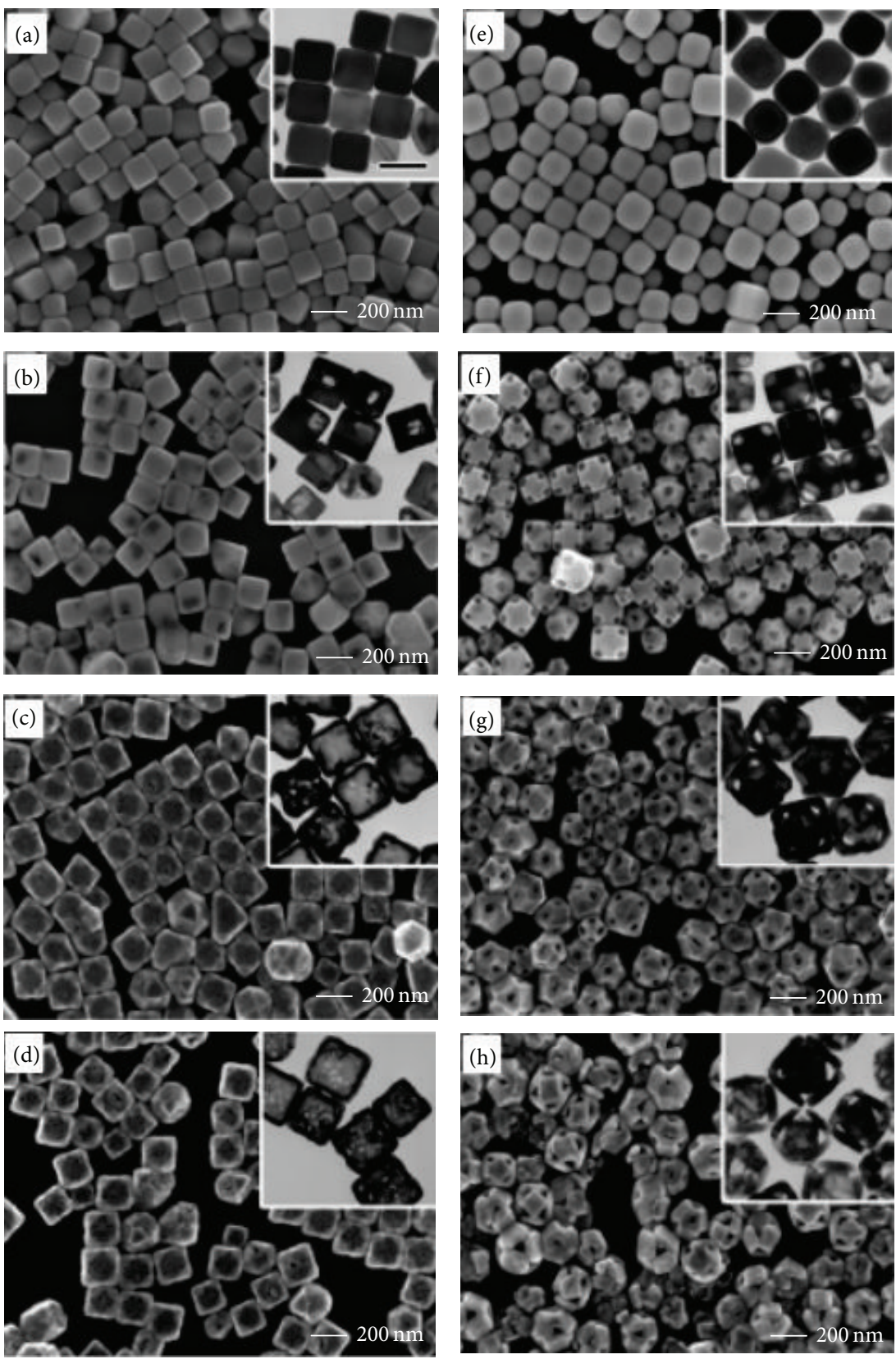

FIGURE 4: SEM images of four different stages of galvanic replacement reaction with Ag nanocubes serving as the sacrificial template. (a)(d) Ag nanocubes with sharp corners titrated. (e)-(h) Ag nanocubes with truncated corners reacted. (Adopted with permission from [111]. Copyright 2006 American Chemical Society.)

the polyethylenimine and polyacrylic acid simultaneously with $\mathrm{Ag}$ and $\mathrm{Au}$ ions followed by thermal treatment leading to formation of nanoparticles. Their study illustrates the role of several parameters such as $\mathrm{pH}$, type of polymers, and reduction approach in formation and shape of $\mathrm{AuAg}$ nanoparticles. Zhang et al. [124] used underpotential deposition (UPD) combined with redox replacement to fabricate AuAg nanoparticles. They used glassy carbon (GC) as the base and reduced the $\mathrm{HAuCl}_{4}-\mathrm{H}_{2} \mathrm{O}$ in presence of PVP. The UPD method has been employed to deposit a thin layer of $\mathrm{Pb}$ on the prepared $\mathrm{Au} / \mathrm{GC}$ electrode. Morphology of the particles obtained from this strategy is very similar to the particles obtained by Tsai et al. [121].

2.3. AuPd Nanostructures. Bimetallic nanostructures are increasingly being used in fuel cells and sensing applications due to their predominant catalytic properties, AuPd being no exception. It has been shown that the AuPd nanocrystals can act as electrocatalysts for the oxidation of alcohols. The combination of gold and palladium is popular since these metals are miscible at any ratio. Due to the high catalytic activity of Pd and Pt, bimetallic colloids of gold and silver in 


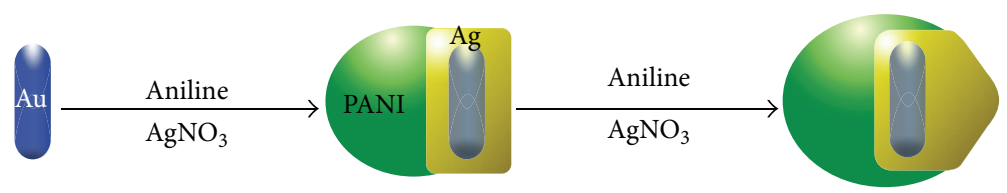

(a)

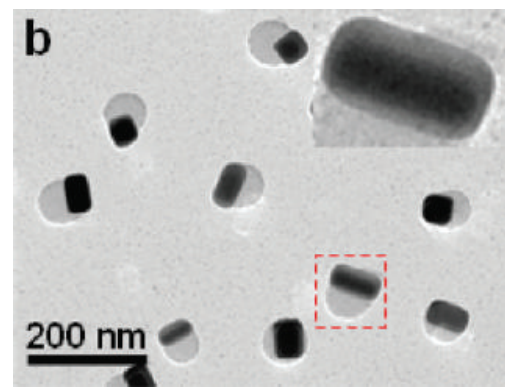

(b)

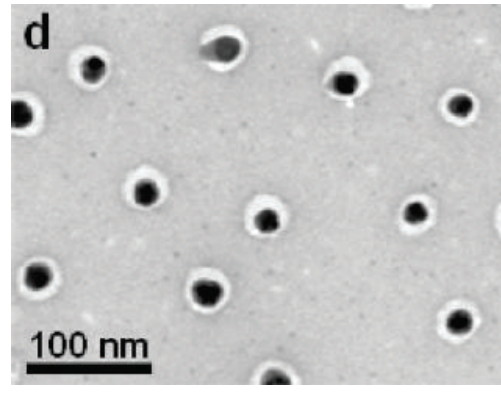

(d)

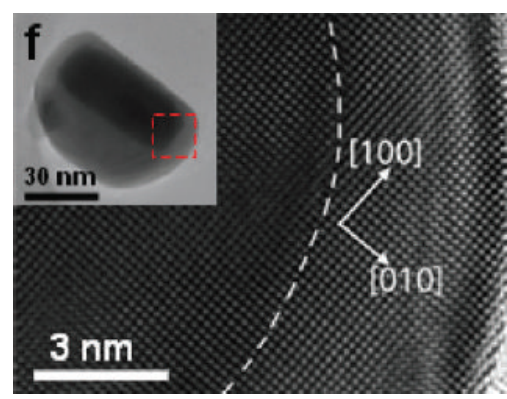

(f)

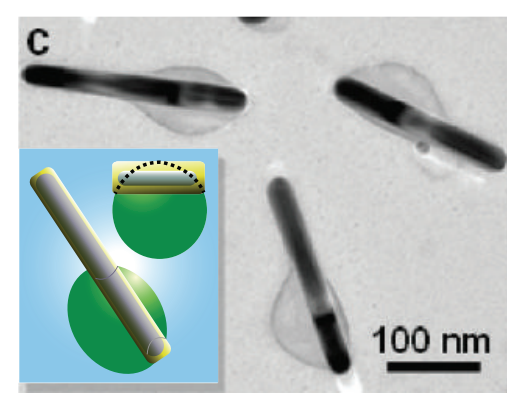

(c)

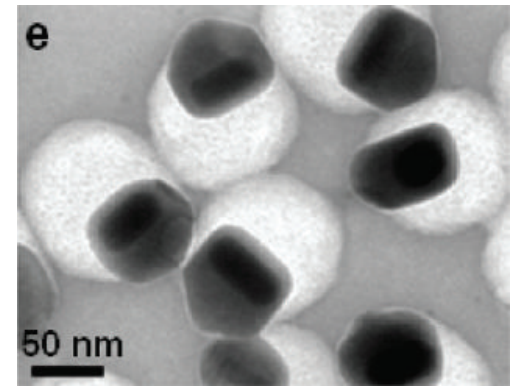

(e)

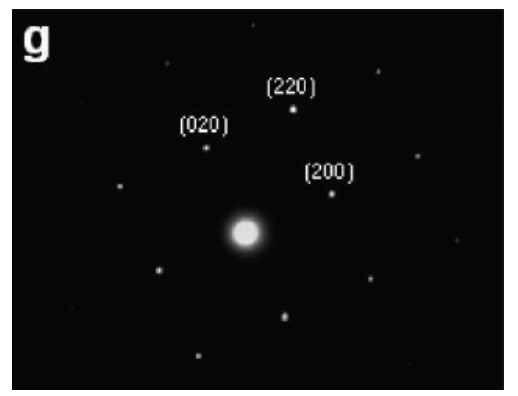

(g)

FIGURE 5: (a) Schematic illustration of the colloidal synthesis of Janus nanoparticles using Au nanorods as seeds. (b, c) TEM images of eccentric PANI infused (AuAg) nanoparticles. (d) Concentric PANI infused (AuAg) nanoparticles. (e) Eccentric (AuAg) and PANI nanoparticles with higher reaction time. (f) HRTEM image of the Au-Ag interface. (g) SAED pattern of an eccentric AuAg core. (Adopted with permission from [115]. Copyright 2011 American Chemical Society.)

combination with Pd and Pt have been studied in great detail. Similar to previous sections these particles can be prepared either in an alloy formation or as a core/shell structure. This section is devoted to the recent advances in preparation of AuPd nanoparticles.

2.3.1. Wet Chemical Reduction. It has been shown that incorporation of $\mathrm{Au}$ into $\mathrm{Pd}$ nanoparticles can reduce the material cost while enhancing their catalytic activity, selectivity, and stability. Camargo et al. [125] reported the synthesis of PdAu hybrid nanostructures in tadpole shapes, with the head being an Au nanoparticle and the tail being a Pd nanorod. The synthesis is based upon the galvanic replacement reaction between single-crystal $\mathrm{Pd}$ nanorods and $\mathrm{AuCl}_{4}{ }^{-}$ions. $\mathrm{HAuCl}_{4}$ was added to $\mathrm{Pd}$ nanorods which dissolves the $\mathrm{Pd}$ into the solution and deposits the Au on the ends of the rod. $\mathrm{Au}$ deposition only occurs at the ends as electrons resulting from the oxidation of $\mathrm{Pd}$ tend to be separated as far as possible. As more $\mathrm{HAuCl}_{4}$ was added, more $\mathrm{Pd}$ would be dissolved from the nanorod which causes further deposition 

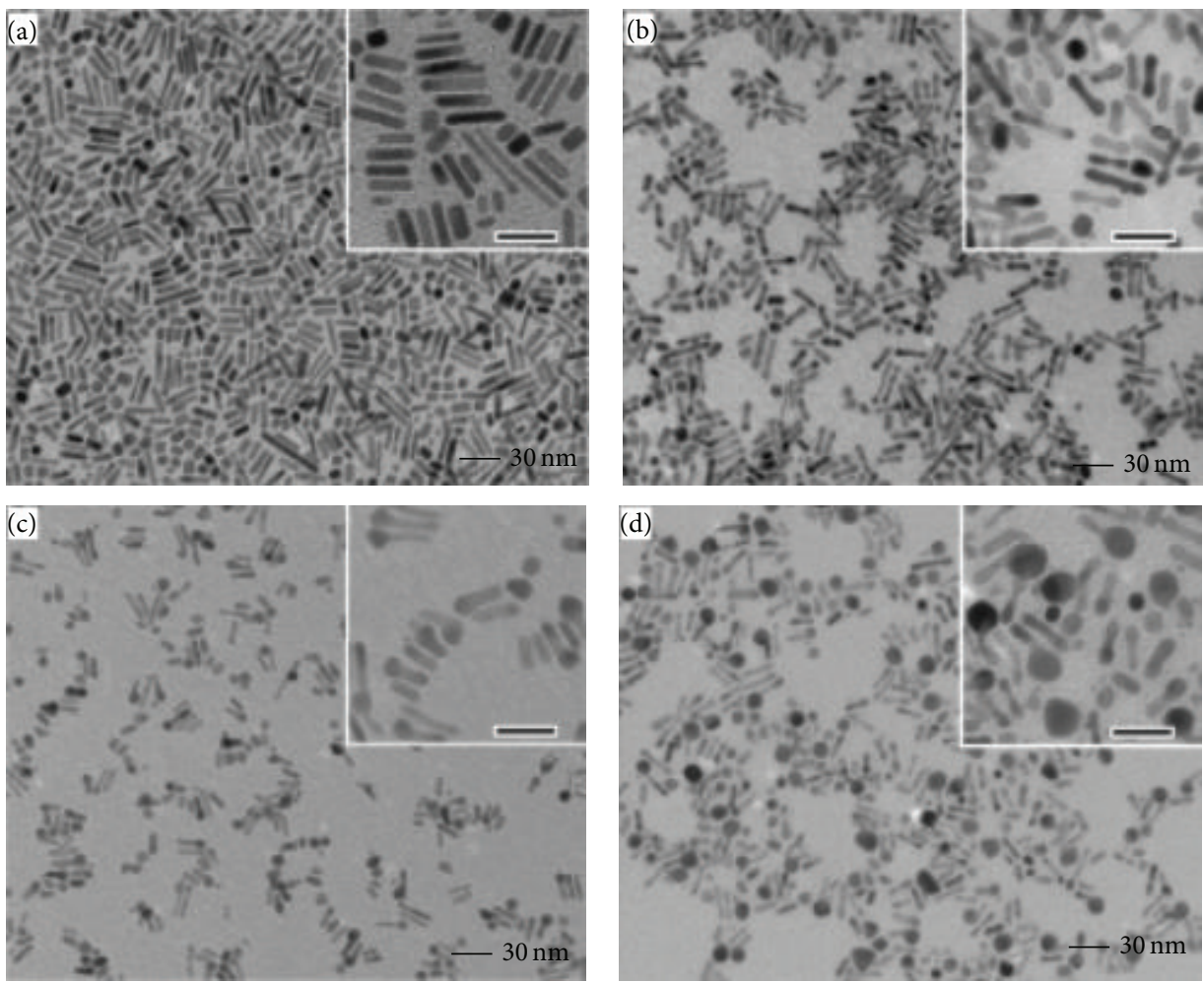

Figure 6: TEM images of (a) Pd nanorods and (b)-(d) samples that were obtained by titrating the Pd nanorods with different volumes. (Adopted with permission from [125]. Copyright 2007 American Chemical Society.)

of Au onto both ends of the rods. However at some point the deposition makes a transition to one-end growth and forms the particles shown in (Figure 6). Lee et al. [126] utilized ascorbic acid as a reducing agent and PVP as a stabilizing agent to synthesize AuPd nanoparticles. They observed that the nanoparticles inside the solution consolidate into the three-dimensional flower-shaped nanoparticles. Ksar et al. [127] devised a method by which they were able to prepare spherically shaped nanoparticles of $\mathrm{PdAu}$ with $\mathrm{Pd}$ acting as shell on the gold rich $\mathrm{Au}$ and used $\mathrm{Pd}\left(\mathrm{NH}_{3}\right)_{4} \mathrm{Cl}_{2}$ and $\left[\mathrm{Au}(\mathrm{en})_{2}\right] \mathrm{Cl}_{3}$ as metallic salts and surfactant cetyltrimethylammonium bromide $(\mathrm{CTAB})$ as the reducing agent while being exposed to $\gamma$-irradiation.

Later in 2009, Lee et al. [112] for the first time devised a one-step aqueous synthesis of core/shell AuPd nanoparticles with a well-defined octahedral shape. They used an aqueous solution of $\mathrm{HAuCl}_{4} / \mathrm{K}_{2} \mathrm{PdCl}_{4}$ in equal proportions in presence of CTAC to prepare the nanoparticles in $90^{\circ} \mathrm{C}$ under various reaction times up to 48 hours (Figure 7). The obtained nanoparticles show unique electrocatalytic activity as well as optical properties associated with Pd. Lim et al. [128] later for the first time were able to control the morphology and the localized surface plasmon resonance (LSPR) peaks of nanoparticles by carefully choosing the reducing agents and molar mixing of the metallic salts. They were able to produce cubic core/shell PdAu nanoparticles by reducing the $\mathrm{HAuCl}_{4}$ with L-ascorbic acid on Pd nanocubes. Same group later in 2010 used the hydrazine as the reducing agent to coreduce the $\mathrm{HAuCl}_{4}$ and $\mathrm{K}_{2} \mathrm{PdCl}_{4}$ in aqueous solutions [72]. As a result they observed the formation of nanodendrites due to the fast reduction rate of metal ions and subsequent fast growth of the particles (Figure 8).

Mazumder et al. [129] later reported a method which could control the thickness of the Au deposit on the Pd nanoparticles. They similarly used Pd (acac) $)_{2}(\mathrm{acac}=$ aceylacetonate) for preparing the $\mathrm{Pd}$ seeds then used the $\mathrm{HAuCl}_{4}$ in presence of oleylamine $(\mathrm{OAm})$ at $80^{\circ} \mathrm{C}$ to deposit the $\mathrm{Au}$. Zhan et al. [130] proposed an entirely ecofriendly and fast method for preparation of the AuPd bimetallic nanoparticles. They used the cacumen platycladi leaf extract as the reducing agent to coreduce the $\mathrm{Au}$ and $\mathrm{Pd}$ precursors (obtained from $\mathrm{HAuCl}_{4}$ and $\mathrm{PdCl}_{2}$ ) in an aqueous solution. The obtained nanoparticles have a spherical shape (Figure 9).

Liu and Yang [131] proposed a method in which they coreduce the $\mathrm{HAuCl}_{4}$ and $\mathrm{PdCl}_{2}$ in presence of dextran as the reducing agent and maintain the temperature in $100^{\circ} \mathrm{C}$ for 12 hours. The result is bimetallic AuPd foam with interlaced necklaces assembled from granular nanocrystals.

Hong et al. [132] were able to produce octapodal shaped AuPd nanoparticles by selective etching of $\{100\}$ facets of $\mathrm{K}_{2} \mathrm{PdCl}_{4}$ by the $\mathrm{AuBr}_{4}{ }^{-}$. They coreduced the $\mathrm{NaAuBr}{ }_{4} / \mathrm{K}_{2} \mathrm{PdCl}_{4}$ in presence of L-ascorbic acid and CTAC at $50^{\circ} \mathrm{C}$. They observed the effect of $\mathrm{Br}^{-}$reducing the $\mathrm{Au}$ as a function. The high surface energy of the Au atoms on $\{100\}$ is reported to be the main reason for the difference in reduction of various facets of nanoparticles. Recently AuPd nanoparticles are widely being used in diagnostic medicine. Ge and coworkers used an aqueous solution of $\mathrm{Na}_{2} \mathrm{PdCl}_{4}$, 


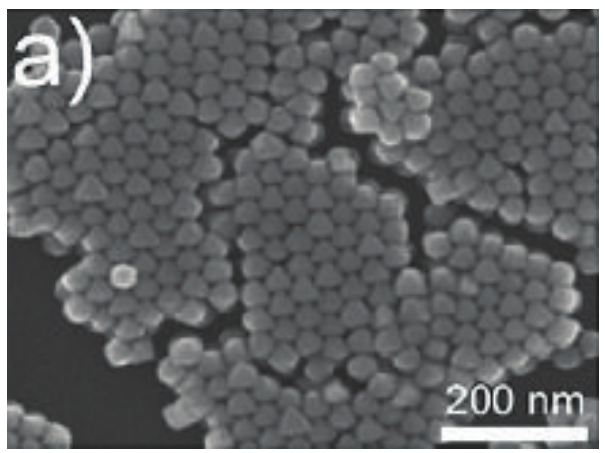

(a)

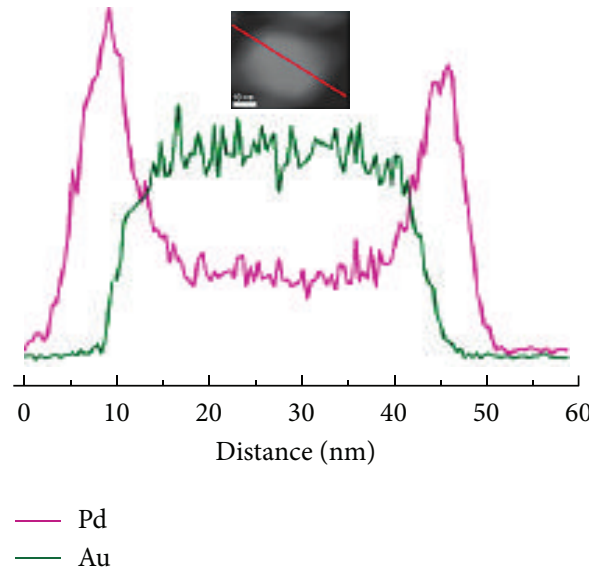

(d)

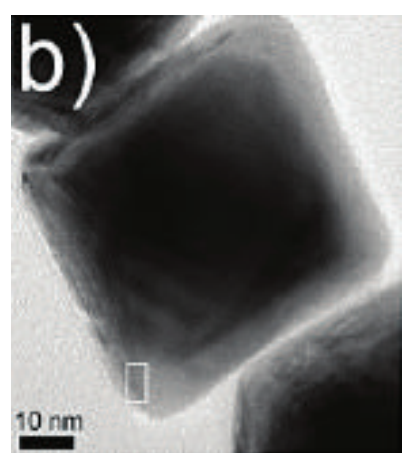

(b)
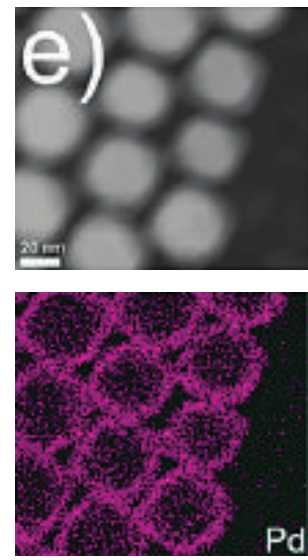

Pd

(e)

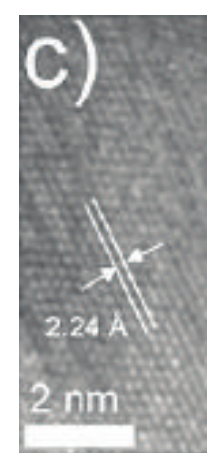

(c)
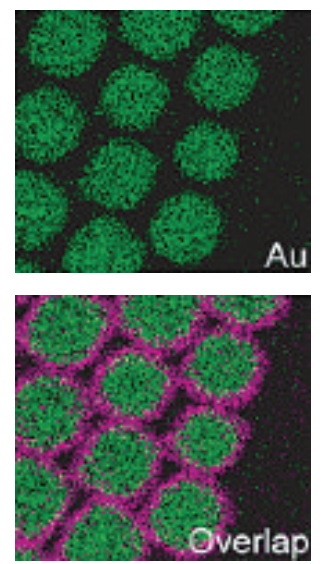

FIGURE 7: (a) SEM and (b) HRTEM images of the AuPd nanooctahedra. (c) High-magnification HRTEM image of the square region in (b). (d) HAADF-STEM image and cross-sectional compositional line profiles of an AuPd nanooctahedron. (e) HAADF-STEM-EDS mapping images of the AuPd nanooctahedra. (Adopted with permission from [112]. Copyright 2009 American Chemical Society.)

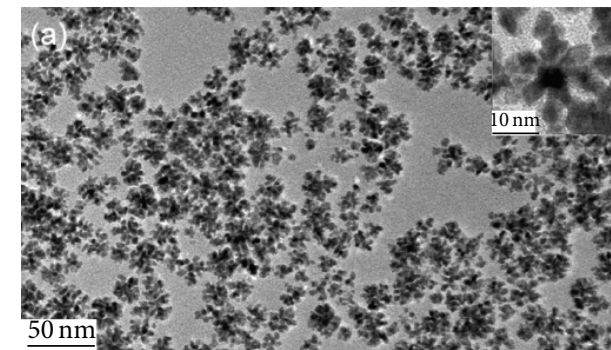

(a)

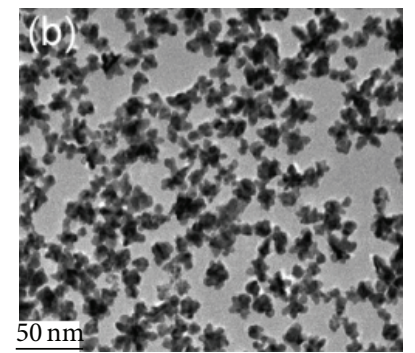

(b)

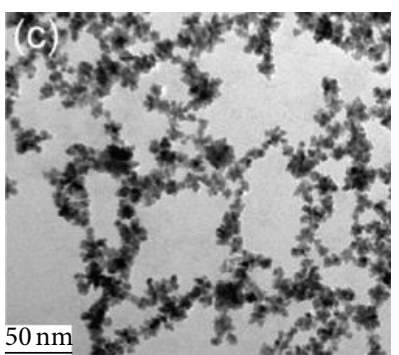

(c)

Figure 8: TEM images of (a) $\mathrm{Au}_{1} \mathrm{Pd}_{1}$, (b) $\mathrm{Au}_{3} \mathrm{Pd}_{1}$, and (c) $\mathrm{Au}_{1} \mathrm{Pd}_{3}$ bimetallic nanoparticles. (Adopted with permission from [72]. Copyright 2010 American Chemical Society.)

$\mathrm{HAuCl}_{4}$, and ascorbic acid as the reducing agent to synthesize AuPd nanoparticles for detecting cancer cells [133]. Table 3 summarizes the key components of wet chemical methods for synthesis of AuPd nanostructures.

2.3.2. Other Methods. Mandal et al. [134] proposed Keggin ion-capped gold nanoparticles after UV illumination as reducing agents while exposing them to $\mathrm{Pd}^{2+}$ and $\mathrm{Pt}^{4+}$ ions for selective reduction of nanoparticles only on the surface. For the first time, they were able to avoid the nucleation of
Pd and Pt nanoparticles in solution. Later a novel method was proposed by Kobayashi et al. to synthesize solid solution nanoparticles with $\mathrm{Pd}$ and $\mathrm{Au}$ being homogeneously mixed at the atomic level with various varying atomic ratios [135]. They used $\mathrm{H}_{2}$ gas as a reducing agent. They first reduced the $\mathrm{PdCl}_{2}$ by alcoholic reduction reaction and then mixed $\mathrm{HAuCl}_{4}$ in presence of $\mathrm{H}_{2}$ gas. The XRD and TEM tests reveal that the Pd and $\mathrm{Au}$ atoms are homogeneously mixed in the obtained nanoparticles. Zhang et al. [136] recently proposed a procedure to use ionic liquid microemulsion as the reducing 


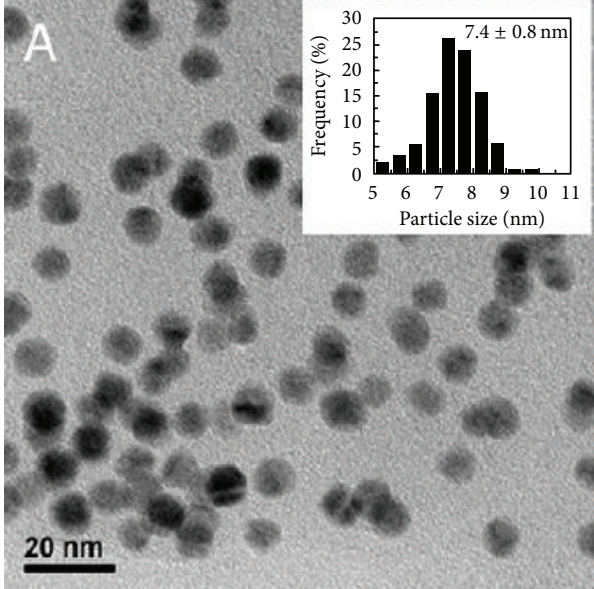

(a)

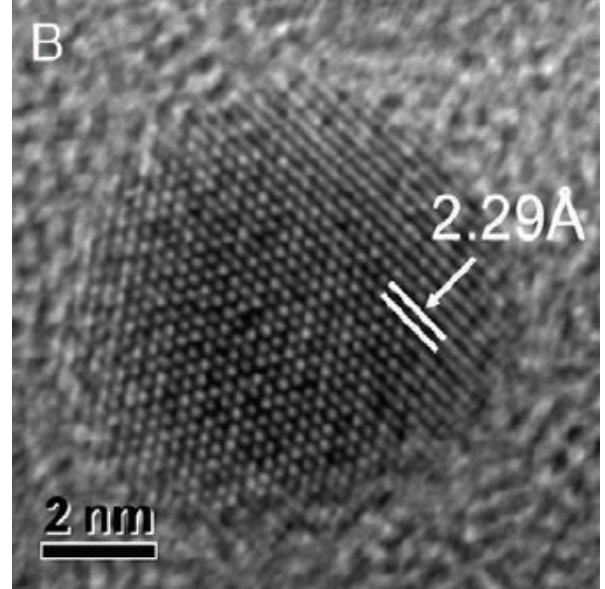

(b)

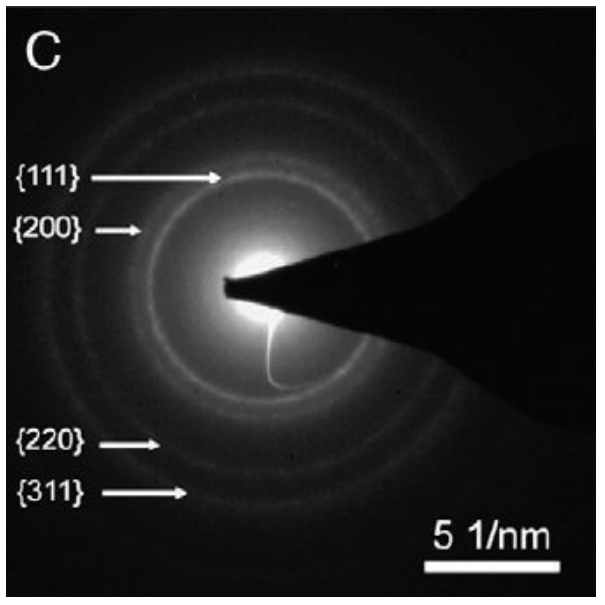

(c)

Figure 9: TEM image (a), HRTEM image (b), and selected area diffraction pattern (c) of the AuPd bimetallic nanoparticles. (Adopted with permission from [130]. Copyright 2011 Elsevier.)

agent. They employed $\mathrm{H}_{2} \mathrm{O}$ /Triton X-100 (TX-100)/1-butyl3-methylimidazolium hexafluorophosphate to reduce the $\left[\mathrm{PdCl}_{6}\right]^{2-}$ ions. Their method produces $\mathrm{Pd}_{4} \mathrm{Au}$ small sized nanoparticles with a uniform size distribution. In 2013, He and coworkers [137] developed a method to produce AuPd nanoparticles without the need to reducing agents. They used grapheme oxide $(\mathrm{GO})$ to simultaneously reduce both $\mathrm{Au}$ and Pd and form a stable suspension of AuPd nanoparticles. The proposed method is important from environmental standpoint as there are no reductants being used and since the product AuPd nanoparticles/GO catalyst is recyclable. Finally Chen et al. in 2014 have used electrodeposition of Pd particles on $\mathrm{Au}$ substrate to create DNA modified sensors for $\mathrm{Pb}$ ion detection [138].

2.4. $\mathrm{Ag}(\mathrm{M})$ Nanostructures. Ag nanoparticles have recently attracted much attention owing to their excellent properties originating from string surface plasmon resonance and surface-enhanced Raman scattering. It has also been observed that $\mathrm{Ag}$ ions play an important role in regulating the nanocrystal growth [139]. Furthermore, it has been observed that alloying with $\mathrm{Ag}$ improves the catalytic and optical response of the other metal $[102,140]$. However combination of Ag with other metals is less investigated. In this section, we present the latest achievements in preparing bimetallic nanoparticles containing $\mathrm{Ag}$ as one of the constituents. In 2003, He et al. used a stepwise ion-exchange reduction approach to produce AgPd nanoparticles [141]. The ionexchanged sites were prepared on thin $\mathrm{TiO}_{2}$ films using $\mathrm{Mg}^{2+}$ ion. The $\mathrm{Ag}^{+}$and $\mathrm{Pd}^{2+}$ ions then replace the $\mathrm{Mg}^{2+}$ ions using the reducing $\mathrm{H}_{2}$ plasma. Their product demonstrates an improved catalytic activity of 367 times more than that of Pd black and 1.6 times more than that of Pd monometallic nanoparticles. Their research has been a successful try for synthesis of bimetallic nanoparticles using a facile and energy efficient method; however, the proposed method had little control over the morphology of the nanoparticles. Later, Liu et al. used ethanol combined with HCHO to modify the seeding process of Ag preparation and were able to achieve uniform shell-core and hollow $\mathrm{CuAg}$ and PtAg nanoparticles [142]. 


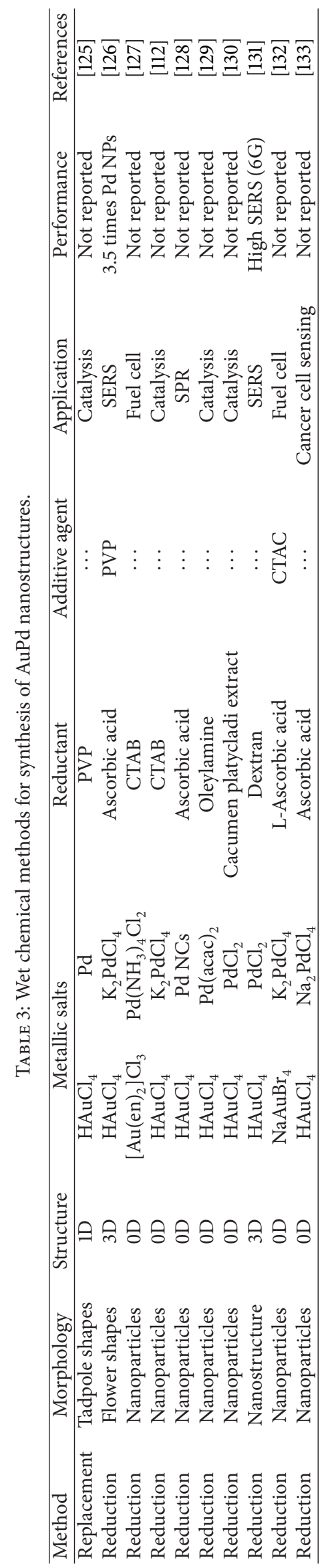



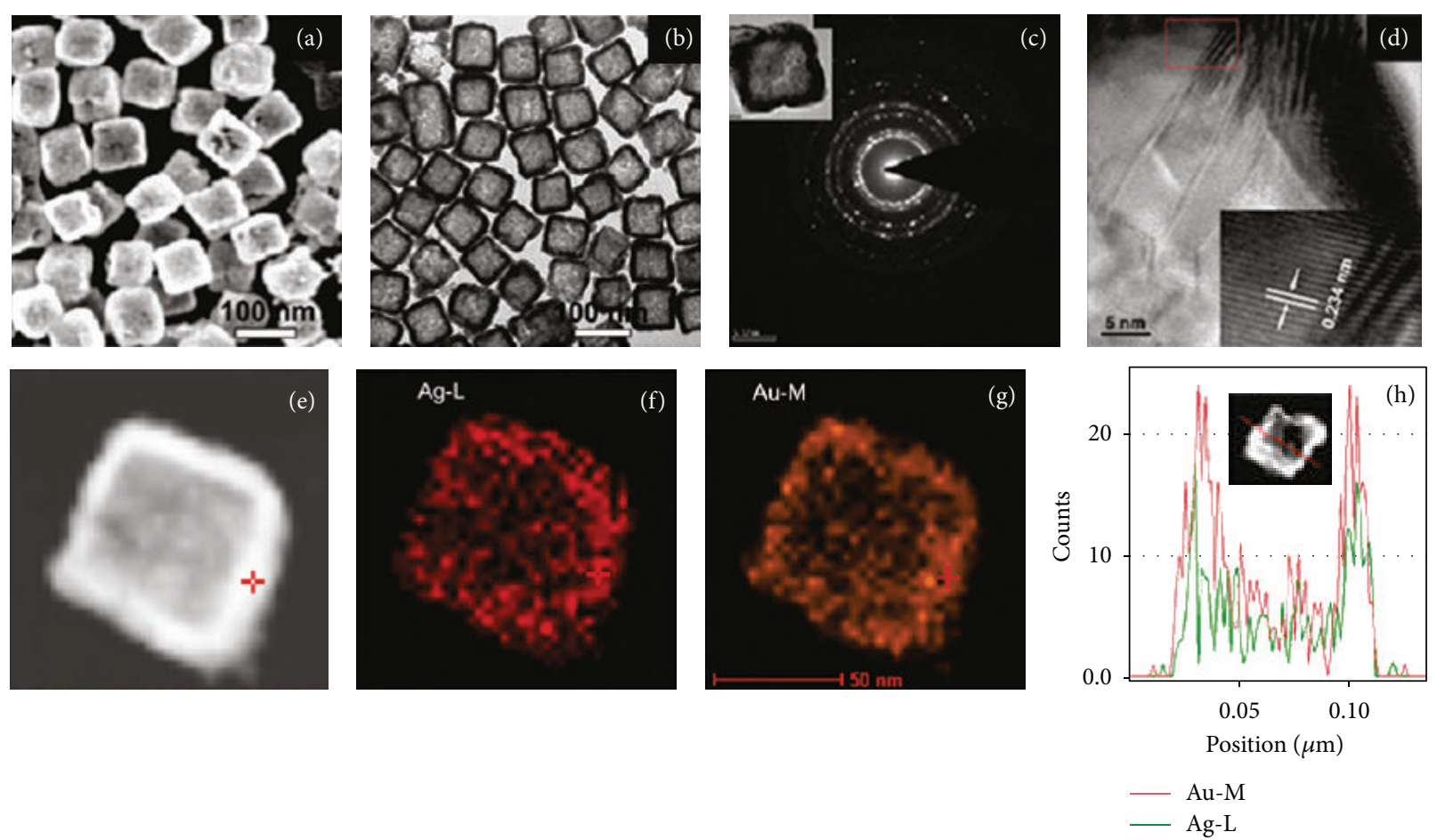

Figure 10: Typical (a) SEM and (b) TEM images of AgAu nanoboxes; (c) electron diffraction pattern of a single nanobox; (d) HRTEM image near the box wall; (e) HAADF/STEM image; (f, g) STEM/EDX element mappings of Ag and Au, respectively; and (h) cross-section composition line profiles of one nanobox. (Adopted with permission from [146]. Copyright 2010 American Chemical Society.)

Lee et al. [143] used the simultaneous reduction of $\mathrm{Pd}(\mathrm{OAc})_{2}$ and $\mathrm{AgNO}_{3}$ in presence of SDS to produce core/shell nanoparticles with more concentration of Pd on the shell. They were also able to control the size of the nanoparticles by changing the proportion of the $\mathrm{Ag}$ and $\mathrm{Pd}$ ions concentration. Gao et al. [144] showed that successive reduction of $\mathrm{AgNO}_{3}$ and $\mathrm{H}_{2} \mathrm{PtC}_{16}$ using hydrazine will create hollow bimetallic nanoparticles with controllable plasmon resonance peaks. Xu and coworkers [145] used diphenyl ether (DPE) to deposit Pt on Ag nanoparticles to prepare hollow Pt nanoparticles. However, their work is presented here in regard to their synthesis process. Later in 2010, He et al. [146] proposed a fast method to prepare hollow and porous nanoparticles with $\mathrm{Ag}$ being the parent metal combined with other metals, for example, Au, Pt, and Pd. They used Lascorbic acid to reduce the different aqueous metallic salt solutions. They report that the surfactant CTAB molecules greatly affect the morphologies of the obtained nanoparticles (Figures 10 and 11).

Recently, Sachen and coworkers [147] used a pulsed laser dewetting technique on bilayer $\mathrm{Ag}$ and $\mathrm{Co}$ films to make bimetallic nanoparticle arrays. Thickness of individual layers as well as the arrangement of the layers controls the size characteristics of nanoparticles. Although their method is not considered to be a facile method, here we report it as one of the recently established routes in processing the Ag nanoparticles. In 2013, Szyman'ska reported a chemical vapor deposition technique to synthesize $\mathrm{AgCu}$ nanoparticles [148]. The $\left[\mathrm{Ag}\left(\mu-\mathrm{O}_{2} \mathrm{CC}_{2} \mathrm{~F}_{5}\right)\right]_{\mathrm{n}}$ and
$\left[\mathrm{Cu}\left\{\mathrm{CH}_{2}=\mathrm{C}(\mathrm{H}) \mathrm{SiMe}_{3}\right\}\left(\mu-\mathrm{O}_{2} \mathrm{CC}_{2} \mathrm{~F}_{5}\right)\right]_{\mathrm{m}}$ were used as precursors under high pressure and temperature to deposit the $\mathrm{Ag}$ and $\mathrm{Cu}$ particles on $\mathrm{Si}$ substrate. The proposed method however is costly and is not accessible for general use.

2.5. Cu (M) Nanostructures. Studies of catalytic reduction of nitrates indicate the efficacy of bimetallic nanosized catalysts compared to their monometallic counterparts. These catalysts are often the combination of a metal from transition group of periodic table (i.e., $\mathrm{Cu}$, $\mathrm{Fe}$, etc.) with a nobel metal (i.e., $\mathrm{Pd}, \mathrm{Pt}$, etc.). $\mathrm{Cu}$ based bimetallic nanoparticles are proven to be efficient in catalytic reaction, for example, in nitrate reduction; hence they are discussed in this section. Liu et al. [149] proposed a colloidal method for synthesis of $\mathrm{CuPt}$ nanorods that could yield results in less than an hour. They proposed mixing of $\mathrm{Pt}(\mathrm{acac})_{2}, \mathrm{Cu}(\mathrm{acac})_{2}, 2$ hexadecanediol, oleic acid, oleylamine (as a stabilizer), and 1-octadecene all at once and heating the solution first up to $120^{\circ} \mathrm{C}$ for 20 minutes and then up to $225^{\circ} \mathrm{C}$ for 30 minutes. The result is a combination of $\mathrm{CuPt}$ nanorods and with a small portion of nanospheres that are separated using centrifugation (Figure 12). They also report that an increase in molar ratio of oleylamine will increase the length of nanorods while the same effect can be obtained by using diphenyl ether and dibenzyl ether as solvents. Other nanoparticle shapes such as monodisperse spherical CuPt nanocrystals can also be obtained in shorter heating times and lower temperatures. Even $\mathrm{CuPt}$ nanocubes can be synthesized by using larger portions of 1,2-hexadecanediol. 

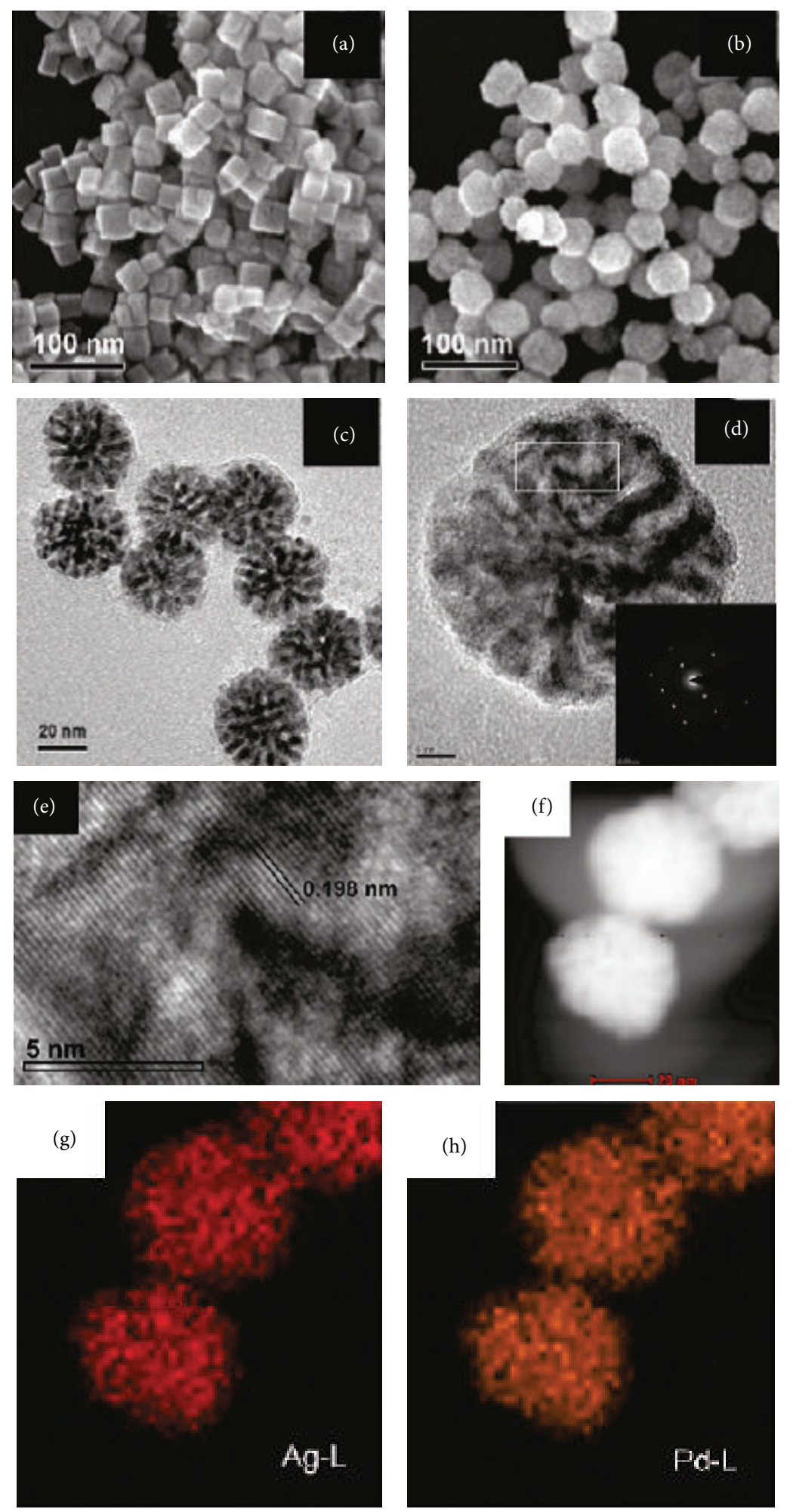

FIGURE 11: SEM image of (a) Pd nanocubes and (b) SEM, (c) TEM, and (d) HRTEM images of branched AgPd nanocrystals, (e) is the enlarged image of the white box in panel (d), (f) HAADF/STEM image and STEM/EDS element mappings (for (g) Ag and (h) Pd of AgPd nanocrystals. (Adopted with permission from [146]. Copyright 2010 American Chemical Society.) 


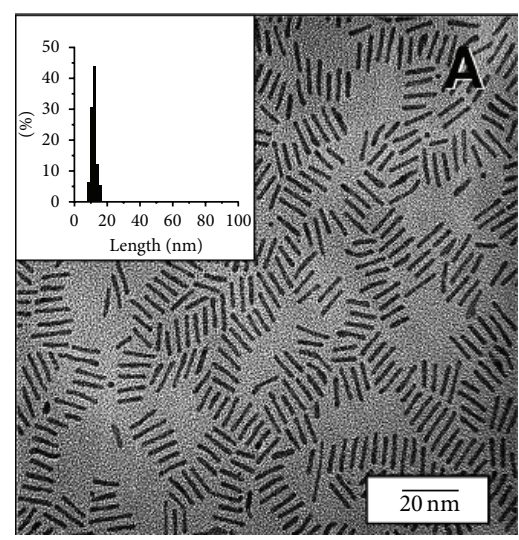

(a)

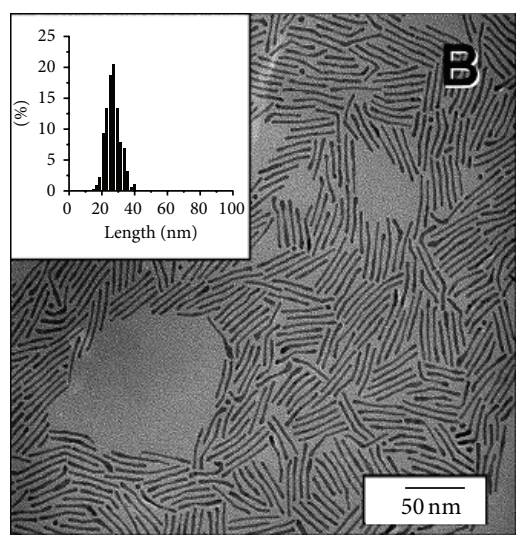

(b)

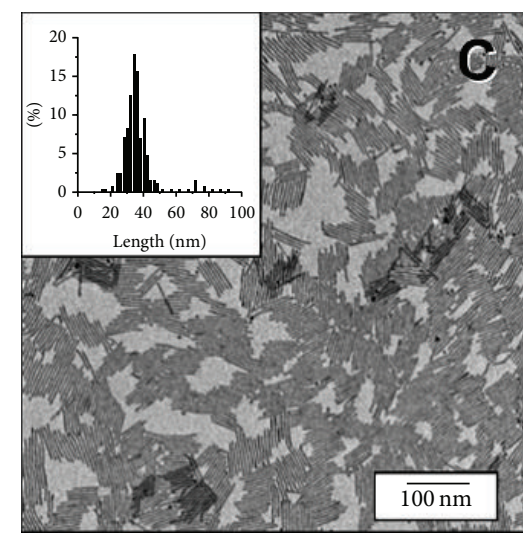

(c)

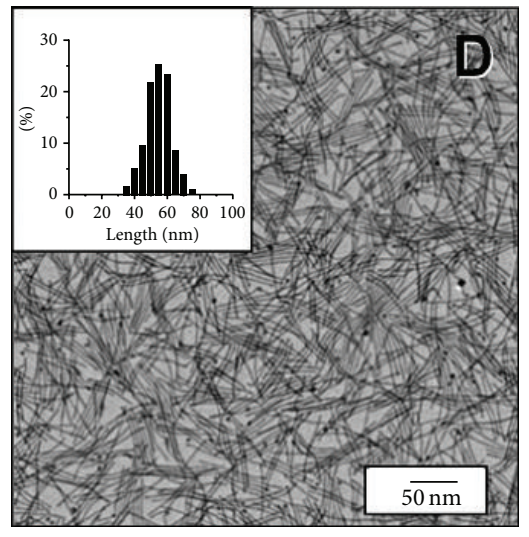

(d)

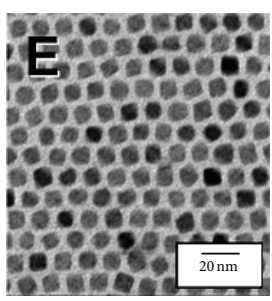

(e)

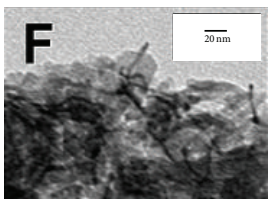

(f)

Figure 12: TEM images of Cu-Pt nanorods with average lengths of (a) 12.6, (b) 27.8, (c) 37.1, and (d) $55.5 \mathrm{~nm}$. (e) Cu-Pt cubes and (f) Cu-Pt nanorod catalyst prior to reaction. (Adopted with permission from [149]. Copyright 2009 American Chemical Society.)

In general, monodisperse cubic nanocrystals are of great interest as building blocks for self-assembly [150, 151]. However up until recently, there has been no report of producing sub-10 nm gold nanoparticles [152]. Liu and Hight Walker proposed a one-step colloidal polyol approach for the synthesis of single crystalline $\mathrm{AuCu}$ nanocubes with controllable size and composition [153]. Their method comprises simultaneous reduction of $\mathrm{Cu}(\mathrm{acac})_{2}$ and $\mathrm{HAuCl}_{4}$ by 1,2-hexadecanediol (HDD) in diphenyl ether (DPE) solvent, in presence of 1-adamantanecarboxylic acid (ACA), 1hexadecylamine (HDA), and 1-dodecanethiol (DDT).

They also performed a number of investigations on the effect of reaction parameters and found out that the size of nanocubes has direct relationship with the amount of DDT, $\mathrm{Cu}(\mathrm{acac})_{2}$, and $\mathrm{HAuCl}_{4}$ present in the reaction. Therefore, by reducing the amount of these agents they were able to obtain nanocubes with edge length of $5 \mathrm{~nm}$ (Figure 13). They also found out that composition of the nanocubes can be controlled by careful adjustment of the same agents while keeping the morphology of the product constant. Mazumder et al. [154] also used a similar approach by reducing $\mathrm{Cu}(\mathrm{acac})_{2}$ and $\mathrm{PdBr}_{2}$ in oleylamine and trioctylphosphine. They were able to control the size and composition of the spherically shaped nanoparticles by carefully adjusting the reaction parameters, for example, heating rate and metal salt molar ratios.

Yu and Zhou [155] recently investigated the process of nanoparticle formation in $\mathrm{CuPt}$ bimetallic nanoparticles. They produced the $\mathrm{CuPt}$ nanoparticles by reducing the $\mathrm{Pt}(\mathrm{acac})_{2}$ and $\mathrm{CuSO}_{4} \cdot 5 \mathrm{H}_{2} \mathrm{O}$ as metallic precursors, in presence of hexadecylamine or PVP as capping agents. Their incremental investigation on crystal morphology of the nanoparticles produced in presence of hexadecylamine reveals that unlike conventional thinking the precursor salts form amorphous clusters in very early stages of reaction (Figure 14). Later in the process these clusters combine and form crystalline islands which are the base for the core/shell structure of the nanoparticles. The crystallization was observed to extend from shell to core. However this form of nanoparticle formation was not observed when PVP was employed as a capping agent and classic formation route was confirmed for this capping agent.

In 2013, Su et al. [156] produced PtCu nanotubes using the conventional galvanic reaction. They first produced the $\mathrm{Cu}$ nanowires by mixing the sodium hydroxide and $\mathrm{Cu}\left(\mathrm{NO}_{3}\right)_{2}$ and the triggering agent $\mathrm{N}_{2} \mathrm{H}_{4}$. The ethanol solution of 

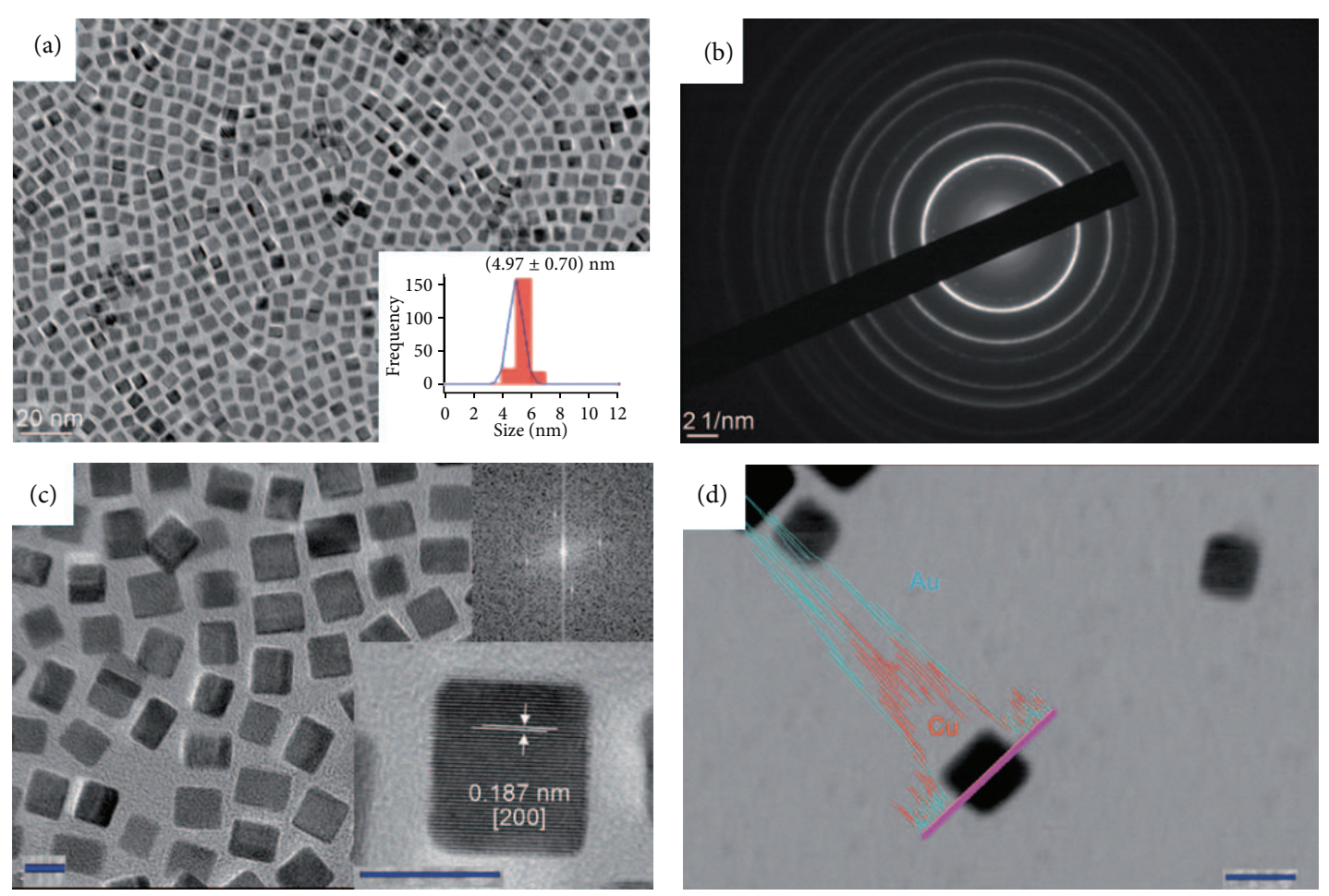

FIGURE 13: (a) TEM image of $\mathrm{AuCu}_{3}$ nanocubes, (b) TEM diffraction pattern, (c) HRTEM of as-prepared nanocubes, and (d) STEM image and the corresponding EDX spectra following a line scanning profile of a single nanocube. The unmarked scale bars represent $5 \mathrm{~nm}$. (Adopted with permission from [153]. Copyright 2010 WILEY-VCH Verlag GmbH \& Co.)

the obtained $\mathrm{Cu}$ nanowires was mixed, $\mathrm{H}_{2} \mathrm{PtCl}_{6} \cdot 6 \mathrm{H}_{2} \mathrm{O}$ with a $\mathrm{Pt}$ to $\mathrm{Cu}$ ratio of 0.5 . The produced $\mathrm{PtCu}$ nanotubes exhibit 10fold improved activity with respect to oxygen reduction reaction. In addition, the durability of the produced nanotubes improved compared to the Pt/C (40\%) and Pt black.

2.6. Pt (M) Nanostructures. Xiao et al. [157] developed a novel nonenzymatic glucose sensor based on PtM ( $\mathrm{M}=$ $\mathrm{Ru}, \mathrm{Pd}$, and $\mathrm{Au}$ ) nanoparticles. In this study, the bimetallic PtM nanocatalysts were prepared on the composite surface of multiwalled carbon nanotubes-ionic liquid by using ultrasonic electrodeposition method. The synthesized PtM nanoparticles were well-dispersed and showed the behaviors of alloy. The atomic ratio of PtM was roughly consistent with the concentration ratio in the electrodeposition solution. Electrochemical observation showed that the PtRu (1:1)-multiwalled carbon nanotubes-ionic liquid modified electrode had large active surface and high electrocatalytic activity for glucose oxidation in neutral solutions. When it was used as a glucose sensor, the linear range, sensitivity, reproducibility, and selectivity were acceptable. They concluded that the novel sensor has potential application in glucose detection. Wu et al. [158] introduced a new approach to prepare ultralow Pt-loading Au flower-like nanostructures using an underpotential deposition process. Electrochemical data depict that this ultralow Pt-loading Au flowerlike nanostructures exhibit excellent electrocatalytic activity towards the reduction of hydrogen peroxide and glucose oxidation. They have also shown good reproducibility and selectivity, a low detection limit, and a wide linear range, which can potentially be utilized as a novel biosensor to analyze applicable samples. Their finding is of importance for the sensing application of bimetallic nanomaterials made by the underpotential deposition redox replacement method. S. Alayoglu et al. [159] investigated the guided synthesis of a nanoparticle catalyst comprising a $\mathrm{Ru}$ core covered with an approximately 1 and 2 monolayer-thick shell of Pt atoms. Next, the distinct catalytic properties of these well-characterized core/shell nanoparticles were studied for preferential $\mathrm{CO}$ oxidation in hydrogen feeds. For $\mathrm{H}_{2}$ streams containing 1000 p.p.m. CO, the $\mathrm{H}_{2}$ lightoff is complete by $30^{\circ} \mathrm{C}$, which is significantly better than for traditional PtRu nanoalloys $\left(85^{\circ} \mathrm{C}\right)$, monometallic mixtures of nanoparticles $\left(93^{\circ} \mathrm{C}\right)$, and pure Pt particles $\left(170^{\circ} \mathrm{C}\right)$. Furthermore, density functional theory studies suggest that the improved catalytic activity for the core/shell nanoparticle originates from a combination of an increased availability of CO-free Pt surface sites on the RuPt nanoparticles and a hydrogen-mediated low-temperature $\mathrm{CO}$ oxidation process that is obviously distinct from the traditional bifunctional CO oxidation mechanism reported in the literature. Guo and Sun [160] developed a facile solution-phase self-assembly method to deposit FePt nanoparticles on the graphene surface. Based on this study, the graphene/FePt nanoparticles show enhanced catalytic activity and durability for oxygen reduction reaction (ORR) in $0.1 \mathrm{M} \mathrm{HClO}_{4}$ solution. Especially, the graphene/FePt nanoparticles annealed at $100^{\circ} \mathrm{C}$ for $1 \mathrm{~h}$ have ORR activity about 2 times higher than the unannealed graphene/FePt 


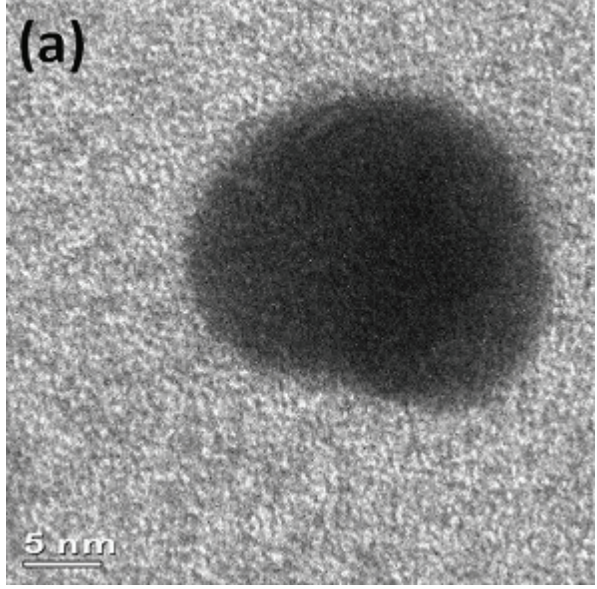

(a)

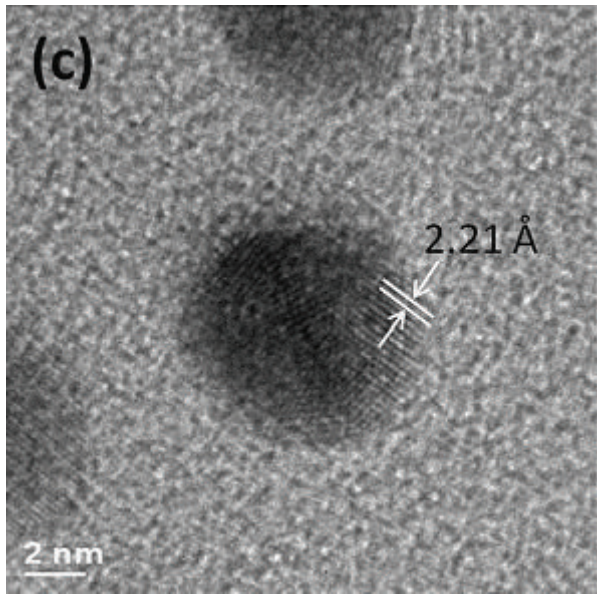

(c)

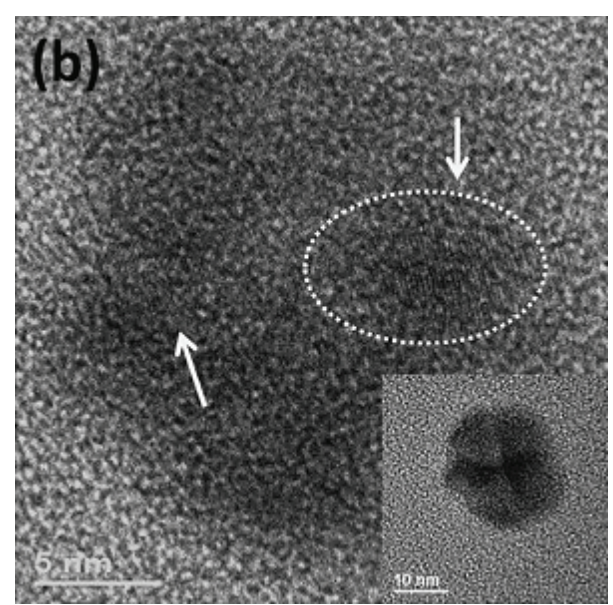

(b)

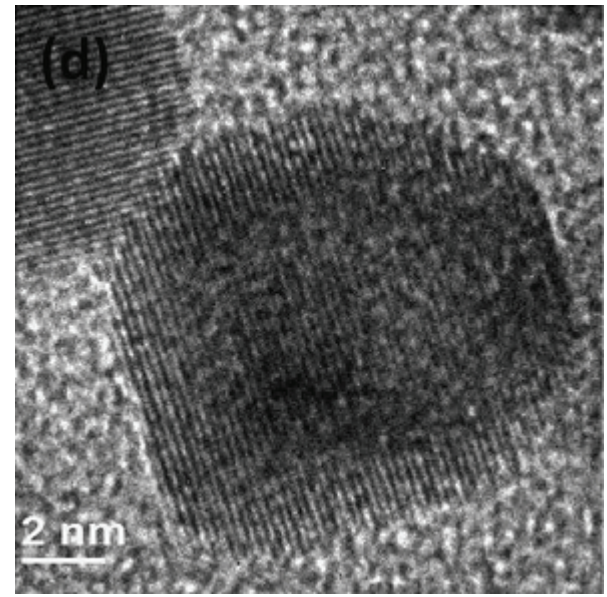

(d)

FIGURE 14: HRTEM images from specimens of CuPt nanoparticles after different reaction times: (a) 6 min; (b) 8 min; (c, d) HRTEM images of nanoparticles after heating for $0.5 \mathrm{~h}$ and $1.5 \mathrm{~h}$, respectively. (Adopted with permission from [155]. Copyright 2013 Elsevier.)

nanoparticles, 3.7-4.5 times higher than the graphene/FePt nanoparticles, and 5.9-8.8 times higher than the commercial graphene/ $\mathrm{Pt}$ nanoparticles in the reduction potential range of $0.512-0.557 \mathrm{~V}$ (versus $\mathrm{Ag} / \mathrm{AgCl}$ ). The graphene/FePt nanoparticles are also stable under the ORR conditions and show nearly no activity change after 10000 potential sweeps between 0.4 and $0.8 \mathrm{~V}$. This work demonstrates that grapheme is indeed a promising support to enhance nanoparticles activity and durability for ORR. The reported self-assembly method in this study can be generalized to produce various graphene/nanoparticles for catalytic applications. Zheng et al. [161] investigated a simple procedure for the synthesis of $\mathrm{PtSn}$ bimetallic nanoparticle catalyst. The as-prepared PtSn nanoparticles were in a better dispersion with smaller size. Electrocatalytic oxidation of methanol on the PtSn bimetallic nanoparticles showed remarkably enhanced activity and lifetime compared to that of Pt nanoclusters. Wang et al. [162] reported on a facile and environment-friendly method to synthesize intermetallic $\mathrm{PtPb}$ nanodendrites with controllable compositions (Figure 15). This involves a hydrothermalassisted coreduction of $\mathrm{Pt}$ and $\mathrm{Pb}$ inorganic precursors by formic acid in an aqueous solution without the use of any surfactant. Their systematic structural characterization and in situ electrochemical infrared spectroscopic studies of the formed $\mathrm{PtPb}$ nanodendrites show that the underlying morphogenesis, resulting from the intermetallic phase evolution from a Pt-based face-centered cubic (FCC) to a $\mathrm{PtPb}$ hexagonal type, is responsible for the significant improvement in electrocatalytic activities toward the electrochemical oxidation of formic acid. They have expected these intermetallic compounds with novel dendritic morphology to show versatile technological applications, such as metal alloying and processing, surface plasmon-related research topics, design of novel bio- and chemical sensors, and fuel cell catalyst development. In addition to their important physical properties, the advanced hierarchical structures of the as-synthesized nanodendrites are expected to hold great potential for assembling hybrid functional nanodevices and nanosystems.

2.7. Pd (M) Nanostructures. Li et al. synthesized [163] PdCo bimetallic hollow nanospheres of about $80 \mathrm{~nm}$ diameter 

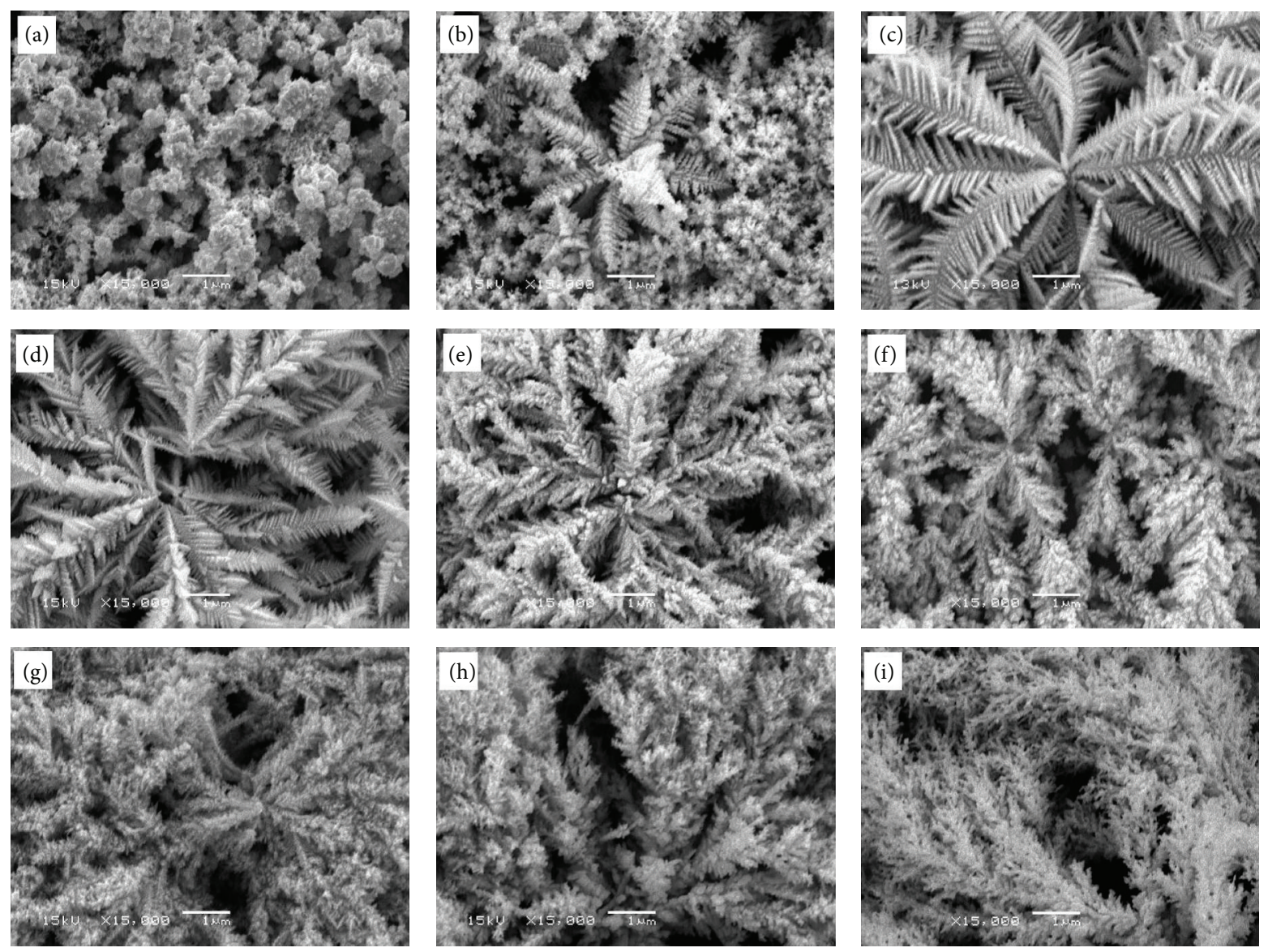

FIGURE 15: SEM migrographs of the as-synthesized Pt-containing nanostructures. (Adapted with permission from [162]. Copyright 2009 American Chemical Society.)

size and of about $9 \mathrm{~nm}$ thickness by use of polyethylene glycol solution. They reported this synthesis route as the first example of Pd-containing bimetallic hollow nanospheres using soft template synthesis. Furthermore, this method was successfully used to catalyze the Sonogashira reaction, which reveals obvious advantages such as environmentally friendly reaction conditions (the reaction proceeded in water), the recyclability of the catalyst, simple experimental operation, and high yields. It is also a new application of PdCo nanoparticles in organic synthesis. Similar fabrication of Co, Pd$\mathrm{Ni}, \mathrm{Ag}_{2} \mathrm{~S}$, and CdS hollow spheres via polyethylene glycolassisted route suggests that this facile, fast, and effective method can be extended to prepare a variety of nanoscale hollow spheres.

Wang et al. [164] reported on a simple method for the fabrication of Pd-rich $\mathrm{Pd}_{\mathrm{x}} \mathrm{Co}$ alloy nanoparticles supported on carbon, using an adsorbate-induced surface segregation effect. The electronic properties of Pd were modulated by alloying with different amounts of Co, which can affect the oxygen reduction reaction (ORR) activity. The electrocatalytic activity of the $\mathrm{Pd}_{3} \mathrm{Co} @ \mathrm{Pd} / \mathrm{C}$ nanoparticles for the ORR was reported to enhance by spontaneously depositing a nominal monolayer of Pt. The activities of the different catalysts for the ORR could be correlated with the oxygen adsorption energy and the d-band center of the catalyst surface, as calculated using density functional theory, which is in agreement with previous theoretical studies. They have stated that the materials synthesized herein are promising cathode catalysts for fuel cell applications and the facile synthesis method could be readily adapted to other catalyst systems, facilitating screening of high efficiency catalysts. Caixia and coworkers investigated [165] the fabrication of novel $\mathrm{PdCu}$ bimetallic nanocomposites with hierarchically hollow structures through a simple galvanic replacement reaction using dealloyed nanoporous copper (NPC) as both template and reducing agent. The reaction process was monitored by UV-vis absorbance spectra and X-ray diffraction (XRD), which clearly demonstrate a structure evolution from NPC precursor to a Pd-rich PdCu alloy structure upon the completion of the reaction. Structural characterization by use of SEM and TEM reveals that the replacement reaction between NPC and $\left[\mathrm{PdCl}_{4}\right]^{2-}$ solution results in a nanotubular mesoporous structure with a nanoporous shell, which is comprised of interconnected alloy nanoparticles with size around $3 \mathrm{~nm}$. Based on this study, the resulted PdCu nanostructure shows superior activity toward oxygen reduction reaction (ORR) with a half-wave potential at $0.840 \mathrm{~V}$, which is significantly better than that of the commercial $\mathrm{Pt} / \mathrm{C}$ catalyst. 


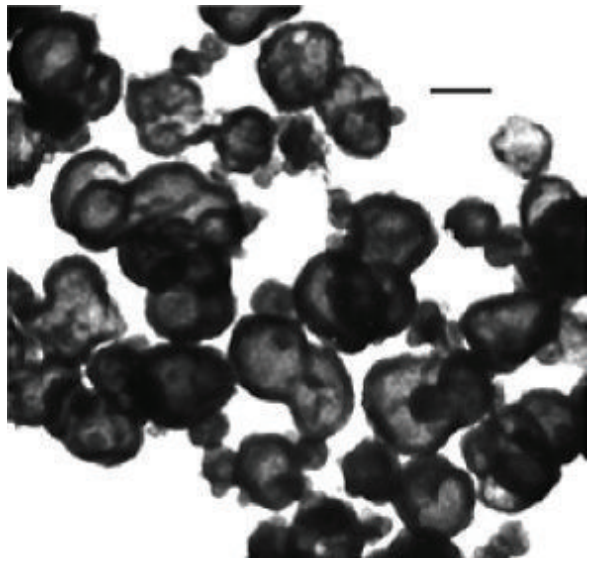

(a)

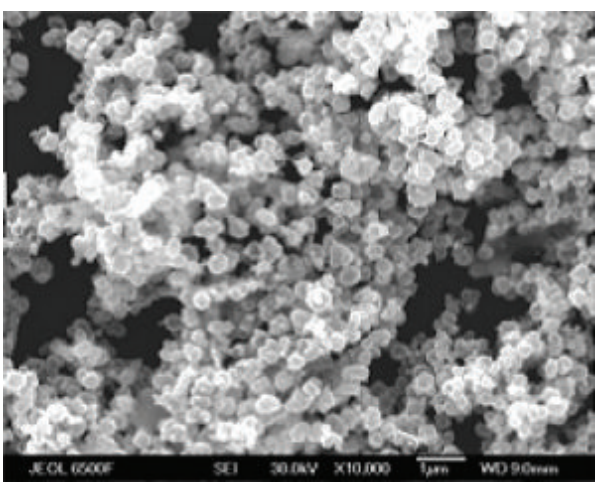

(c)

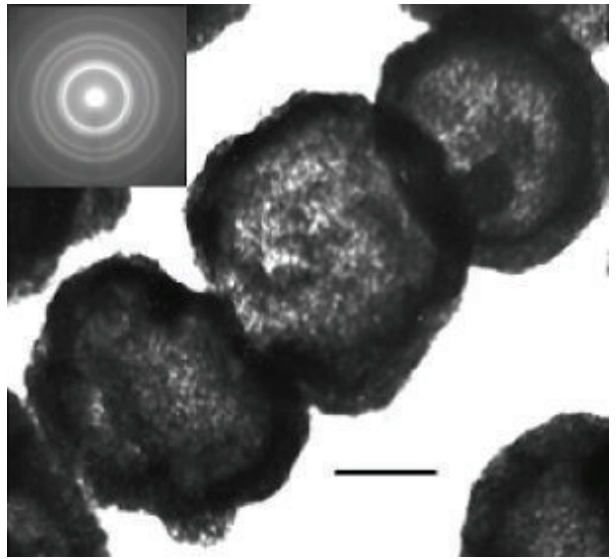

(b)

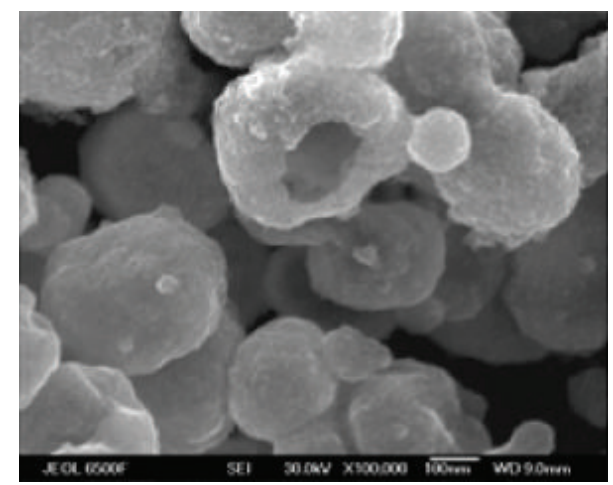

(d)

Figure 16: (a) TEM image of the CoPt hollow spheres with a bar scale of $200 \mathrm{~nm}$; (b) HRTEM image of the CoPt hollow spheres with a bar scale of $100 \mathrm{~nm}$; (c) SEM image of the CoPt hollow spheres with a bar scale of 1 ím; and (d) HRSEM image of the CoPt hollow spheres with a bar scale of $100 \mathrm{~nm}$. (Adapted with permission from [167]. Copyright 2007 American Chemical Society.)

2.8. Co (M) Nanostructures. Han et al. [166] fabricated chainlike $\mathrm{CoCu}$ hollow nanoparticles via a one-pot facile synthesis process, in which Co nanoparticles were reduced by $\mathrm{NaBH}_{4}$ first to provide an in situ template for the formation of the CoCu hollow nanoparticles. Next, they selected the reduction of p-nitrophenol to p-aminophenol by $\mathrm{NaBH}_{4}$ as a model system to evaluate the catalytic activity of the resulting chain-like $\mathrm{CoCu}$ hollow nanoparticles. Interestingly enough, they have seen that the chain-like $\mathrm{CoCu}$ hollow nanoparticles showed high catalytic ability over $\mathrm{Cu}$ nanoparticles due to their higher surface areas. Moreover, the chainlike $\mathrm{CoCu}$ hollow nanoparticles possessed excellent cycle stability and good magnetic property, indicating their great potential applications as catalysts. The method employed in this study may provide a way to synthesize other transition metal nanocomposites for other applications. Chen et al. [167] reported one-step chemical synthesis of CoPt hollow spheres with adjustable composition in an effort to explore new synthesis methods, simplify the synthesis procedure, and improve the synthetic efficiency. In this synthesis, a direct thermolytic reduction of platinum acetylacetonate $\left[\mathrm{Pt}\left(\mathrm{CH}_{3} \mathrm{COHCOCH}\right)_{2}\right]$ and cobalt(II) acetate $\left[\mathrm{Co}\left(\mathrm{CH}_{3} \mathrm{COO}\right)_{2}\right]$ in refluxing ethyl glycol was explored. In the reacting mixture, an anionic surfactant sodium dodecyl sulfate (SDS) was used as the capping and structuredirecting agent. Figure 16 demonstrates TEM images of the synthesized CoPt hollow spheres. These synthesized CoPt hollow spheres demonstrated enhanced electrocatalytic activity toward methanol oxidation in comparison with Pt nanoparticles, which is crucial for anode electrocatalysis in DMFCs. Vasquez et al. [168] reported on the first example of hollow magnetic CoPt nanospheres synthesized through a novel and potentially general one-pot reaction that exploits an in situ sacrificial template. These hollow magnetic nanospheres have important potential applications in drug delivery, catalysis, and composites industries. TEM images of the products are shown in Figure 17. Yan et al. [71] reported a general strategy for preparing magnetically recyclable AuCo core/shell nanoparticles using a one-step seeding-growth method under ambient atmosphere within a short time. Unexpectedly, in contrast to its monometallic and alloy counterparts, the resultant magnetically recyclable AuCo nanoparticles exert excellent catalytic activity and long-term stability toward the hydrolytic dehydrogenation of aqueous $\mathrm{AB}$ under ambient atmosphere at room temperature. Moreover, this rational and general method can be easily 


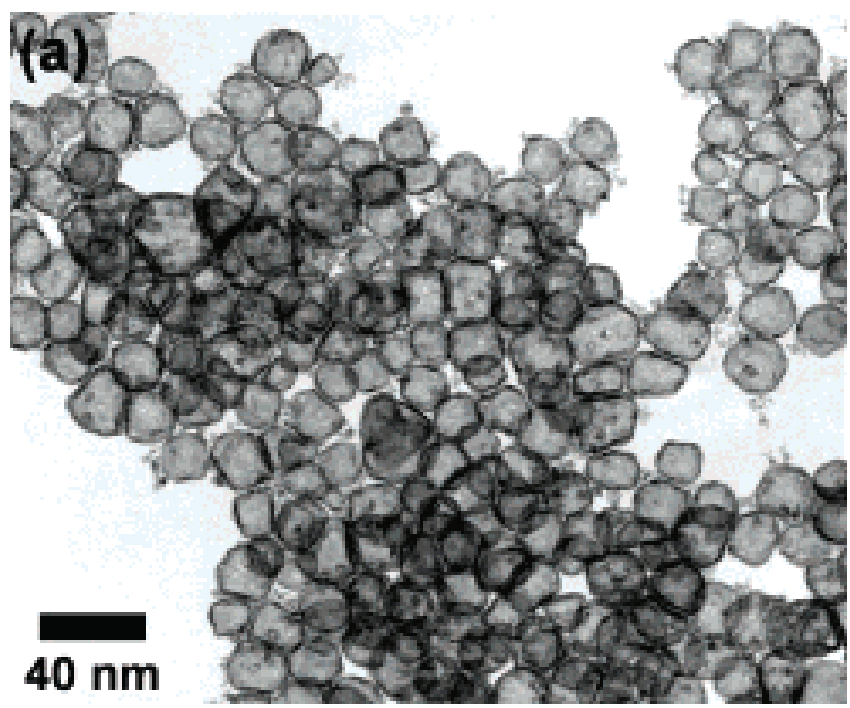

(a)

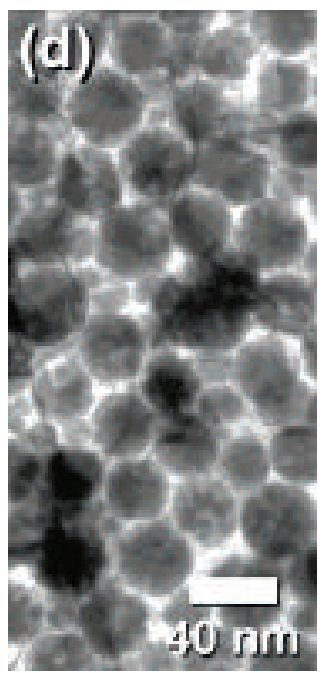

(d)

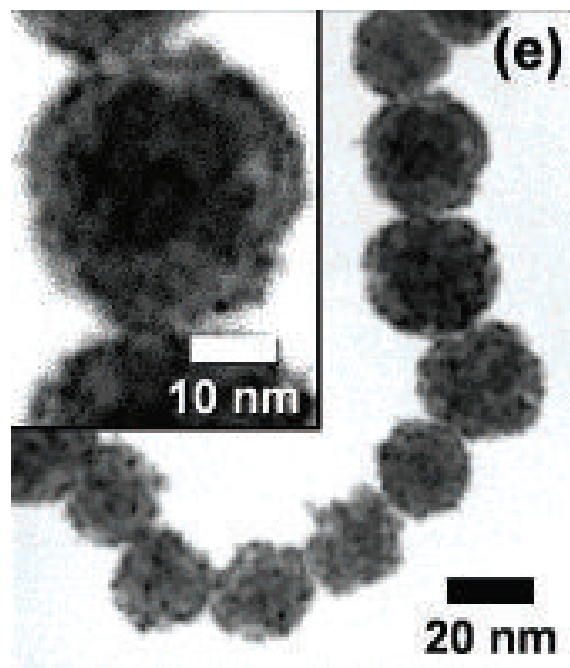

(e)

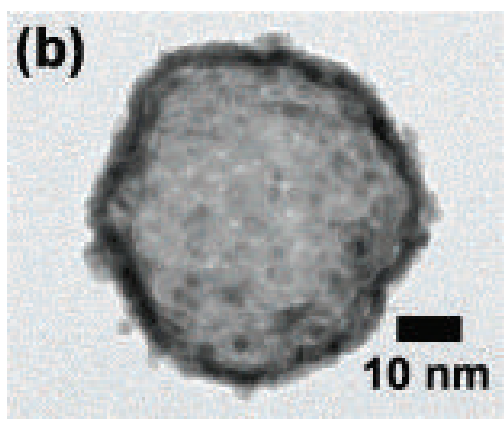

(b)
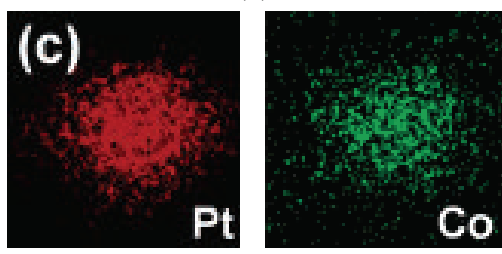

(c)

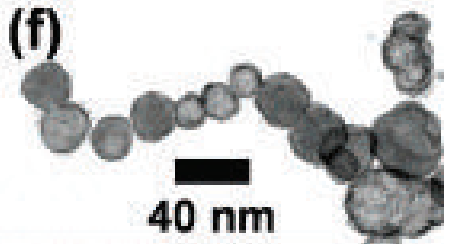

(f)

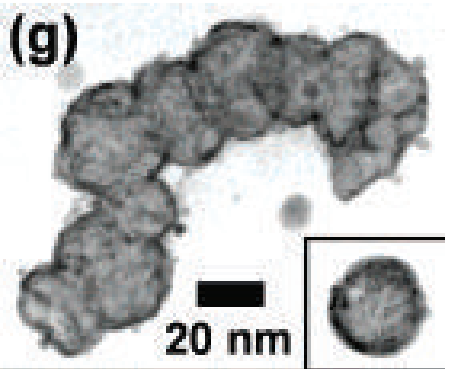

(g)

FIGURE 17: TEM micrographs of (a) CoPt hollow spheres and (b) a single hollow sphere showing that it is comprised of smaller particles; (c) elemental mapping data (Co and Pt) for the sphere in (b); TEM micrographs of (d) the Co nanoparticle template generated in situ and CoPt samples taken after reaction times of (e) $1 \mathrm{~min}$ and (f) $5 \mathrm{~min}$. The hollow structures remain stable after heating to $300^{\circ} \mathrm{C}$ on a TEM grid (g). (Adapted with permission from [168]. Copyright 2005 American Chemical Society.)

extended to the other metallic systems, which are used as optical, magnetic, and electrical materials as well as heterogeneous catalysts.

\section{Conclusions}

Synthesis of bimetallic nanocrystals with controlled morphologies has attracted much attention during the last decade based on their efficiency in various applications particularly in catalysis, sensing, and drug delivery. Among several methods, wet chemical (colloidal) synthesis methods have been more popular due to their ease of use and their potential for implementing environmentally friendly production routes. We categorize these methods into four groups, namely, continuous growth, crystalline coalescence, core/shell growth, and galvanic replacement. Based on the type of application, each of the above may be preferred; however, to the best of our knowledge galvanic replacement and core/shell growth methods are the two most preferred synthesis methods in the recent years. In these methods, it has been observed that the morphology of the product is dependent on many factors, most importantly temperature of the reaction, reaction duration, facet bias of capping agents, and reduction potential of any of the involved agents. Despite recent advances in controlling the morphologies of nanostructures, the literature suggests that only the morphology of the Pt and Pd based nanocrystals can readily be determined while the similar control is not evident for other noble metals. Recent literature in this field suggests that researchers are employing organic and less powerful reductants to reduce the environmental 
impact associated with the production of these materials. However, use of such materials inhibits the use of nonnoble metals that are readily available with less cost. Despite the performance of the products (multiple times better than the parent metals) and the advances in producing them, many of the proposed methods which are only applicable in laboratory scale are still expensive to be implemented in the industrial scale. Addressing the above limitations opens up new avenues for future research.

\section{Conflict of Interests}

The authors declare that there is no conflict of interests regarding the publication of this paper.

\section{Authors' Contribution}

Arash Dehghan Banadaki and Amir Kajbafvala contributed equally to this work.

\section{References}

[1] J. H. Bang and K. S. Suslick, "Applications of ultrasound to the synthesis of nanostructured materials," Advanced Materials, vol. 22, no. 10, pp. 1039-1059, 2010.

[2] K. Hemalatha, G. Madhumitha, A. Kajbafvala, N. Anupama, R. Sompalle, and S. Mohana Roopan, "Function of nanocatalyst in chemistry of organic compounds revolution: an overview," Journal of Nanomaterials, vol. 2013, Article ID 341015, 23 pages, 2013.

[3] A. Kajbafvala, H. Ghorbani, A. Paravar, J. P. Samberg, E. Kajbafvala, and S. K. Sadrnezhaad, "Effects of morphology on photocatalytic performance of Zinc oxide nanostructures synthesized by rapid microwave irradiation methods," Superlattices and Microstructures, vol. 51, no. 4, pp. 512-522, 2012.

[4] A. Kajbafvala, J. P. Samberg, H. Ghorbani, E. Kajbafvala, and S. K. Sadrnezhaad, "Effects of initial precursor and microwave irradiation on step-by-step synthesis of zinc oxide nanoarchitectures," Materials Letters, vol. 67, no. 1, pp. 342-345, 2012.

[5] S. Zanganeh, A. Kajbafvala, N. Zanganeh et al., "Hydrothermal synthesis and characterization of $\mathrm{TiO}_{2}$ nanostructures using LiOH as a solvent," Advanced Powder Technology, vol. 22, no. 3, pp. 336-339, 2011.

[6] M. R. Bayati, R. Molaei, H. R. Zargar, A. Kajbafvala, and S. Zanganeh, "A facile method to grow $\mathrm{V}$-doped $\mathrm{TiO}_{2}$ hydrophilic layers with nano-sheet morphology," Materials Letters, vol. 64, no. 22, pp. 2498-2501, 2010.

[7] X. Liu, D. Wang, and Y. Li, "Synthesis and catalytic properties of bimetallic nanomaterials with various architectures," Nano Today, vol. 7, no. 5, pp. 448-466, 2012.

[8] S. Guo and E. Wang, "Noble metal nanomaterials: controllable synthesis and application in fuel cells and analytical sensors," Nano Today, vol. 6, no. 3, pp. 240-264, 2011.

[9] X. Liu and X. Liu, "Bimetallic nanoparticles: kinetic control matters," Angewandte Chemie, vol. 51, no. 14, pp. 3311-3313, 2012.

[10] J. Wu, P. Li, Y.-T. Pan, S. Warren, X. Yin, and H. Yang, "Surface lattice-engineered bimetallic nanoparticles and their catalytic properties," Chemical Society Reviews, vol. 41, no. 24, pp. 80668074, 2012.
[11] C. Tan, X. Huang, and H. Zhang, "Synthesis and applications of graphene-based noble metal nanostructures," Materials Today, vol. 16, no. 1-2, pp. 29-36, 2013.

[12] D. Wang, X. Li, H. Li et al., "Semiconductor-noble metal hybrid nanomaterials with controlled structures," Journal of Materials Chemistry A, vol. 1, no. 5, pp. 1587-1590, 2013.

[13] J. Gu, Y.-W. Zhang, and F. Tao, "Shape control of bimetallic nanocatalysts through well-designed colloidal chemistry approaches," Chemical Society Reviews, vol. 41, no. 24, pp. 80508065, 2012.

[14] M. M. Khin, A. S. Nair, V. J. Babu, R. Murugan, and S. Ramakrishna, "A review on nanomaterials for environmental remediation," Energy and Environmental Science, vol. 5, no. 8, pp. 8075-8109, 2012.

[15] X. Feng, G. Hu, and J. Hu, "Solution-phase synthesis of metal and/or semiconductor homojunction/ heterojunction nanomaterials," Nanoscale, vol. 3, no. 5, pp. 2099-2117, 2011.

[16] J. He, T. Kunitake, and A. Nakao, "Facile in situ synthesis of noble metal nanoparticles in porous cellulose fibers," Chemistry of Materials, vol. 15, no. 23, pp. 4401-4406, 2003.

[17] P. Mohanpuria, N. K. Rana, and S. K. Yadav, "Biosynthesis of nanoparticles: technological concepts and future applications," Journal of Nanoparticle Research, vol. 10, no. 3, pp. 507-517, 2008.

[18] V. Abdelsayed, A. Aljarash, M. S. El-Shall, Z. A. Al Othman, and A. H. Alghamdi, "Microwave synthesis of bimetallic nanoalloys and CO oxidation on ceria-supported nanoalloys," Chemistry of Materials, vol. 21, no. 13, pp. 2825-2834, 2009.

[19] V. Polshettiwar, M. N. Nadagouda, and R. S. Varma, "Microwave-assisted chemistry: a rapid and sustainable route to synthesis of organics and nanomaterials," Australian Journal of Chemistry, vol. 62, no. 1, pp. 16-26, 2009.

[20] K. B. Narayanan and N. Sakthivel, "Green synthesis of biogenic metal nanoparticles by terrestrial and aquatic phototrophic and heterotrophic eukaryotes and biocompatible agents," Advances in Colloid and Interface Science, vol. 169, no. 2, pp. 59-79, 2011.

[21] S. Cai, D. Wang, Z. Niu, and Y. Li, "Progress in organic reactions catalyzed by bimetallic nanomaterials," Chinese Journal of Catalysis, vol. 34, no. 11, pp. 1964-1974, 2013.

[22] S. Zanganeh, M. Torabi, A. Kajbafvala et al., "CVD fabrication of carbon nanotubes on electrodeposited flower-like Fe nanostructures," Journal of Alloys and Compounds, vol. 507, no. 2, pp. 494-497, 2010

[23] H. R. Zargar, M. R. Bayati, H. R. Rezaie et al., "Influence of nano boehmite on solid state reaction of alumina and magnesia," Journal of Alloys and Compounds, vol. 507, no. 2, pp. 443-447, 2010.

[24] S. Zanganeh, A. Kajbafvala, N. Zanganeh et al., "Self-assembly of boehmite nanopetals to form 3D high surface area nanoarchitectures," Applied Physics A: Materials Science and Processing, vol. 99, no. 1, pp. 317-321, 2010.

[25] M. R. Bayati, R. Molaei, A. Kajbafvala, S. Zanganeh, H. R. Zargar, and K. Janghorban, "Investigation on hydrophilicity of micro-arc oxidized $\mathrm{TiO}_{2}$ nano/micro-porous layers," Electrochimica Acta, vol. 55, no. 20, pp. 5786-5792, 2010.

[26] A. Kajbafvala, S. Zanganeh, E. Kajbafvala, H. R. Zargar, M. R. Bayati, and S. K. Sadrnezhaad, "Microwave-assisted synthesis of narcis-like zinc oxide nanostructures," Journal of Alloys and Compounds, vol. 497, no. 1-2, pp. 325-329, 2010. 
[27] M. R. Bayati, H. R. Zargar, R. Molaei, F. Golestani-Fard, N. Zanganeh, and A. Kajbafvala, "MAO-synthesized $\mathrm{Al}_{2} \mathrm{O}_{3}$ supported $\mathrm{V}_{2} \mathrm{O}_{5}$ nano-porous catalysts: growth, characterization, and photoactivity," Applied Surface Science, vol. 256, no. 12, pp. 3806-3811, 2010.

[28] M. Mazloumi, N. Shahcheraghi, A. Kajbafvala et al., “3D bundles of self-assembled lanthanum hydroxide nanorods via a rapid microwave-assisted route," Journal of Alloys and Compounds, vol. 473, no. 1-2, pp. 283-287, 2009.

[29] A. Kajbafvala, M. R. Shayegh, M. Mazloumi et al., "Nanostructure sword-like $\mathrm{ZnO}$ wires: rapid synthesis and characterization through a microwave-assisted route," Journal of Alloys and Compounds, vol. 469, no. 1-2, pp. 293-297, 2009.

[30] M. Mazloumi, S. Zanganeh, A. Kajbafvala et al., "Ultrasonic induced photoluminescence decay in sonochemically obtained cauliflower-like $\mathrm{ZnO}$ nanostructures with surface $1 \mathrm{D}$ nanoarrays," Ultrasonics Sonochemistry, vol. 16, no. 1, pp. 11-14, 2009.

[31] J. P. Samberg, A. Kajbafvala, and A. Koolivand, "PbO networks composed of single crystalline nanosheets synthesized by a facile chemical precipitation method," Materials Research Bulletin, vol. 51, pp. 356-360, 2014.

[32] A. Bharathi, S. Mohana Roopan, Amir Kajbafvala, R. D. Padmaja, M. S. Darsana, and G. Nandhini Kumari, "Catalytic activity of $\mathrm{TiO}_{2}$ nanoparticles in the synthesis of some 2,3disubstituted dihydroquinazolin-4(1H)-ones," Chinese Chemical Letters, vol. 25, no. 2, pp. 324-326, 2014.

[33] M. Mazloumi, S. Zanganeh, A. Kajbafvala, M. R. Shayegh, and S. K. Sadrnezhaad, "Formation of lanthanum hydroxide nanostructures: effect of $\mathrm{NaOH}$ and $\mathrm{KOH}$ solvents," IJE Transactions B: Applications, vol. 21, no. 2, pp. 169-176, 2008.

[34] M. Mazloumi, S. Taghavi, H. Arami et al., "Self-assembly of $\mathrm{ZnO}$ nanoparticles and subsequent formation of hollow microspheres," Journal of Alloys and Compounds, vol. 468, no. 1-2, pp. 303-307, 2009.

[35] A. Lak, M. Mazloumi, M. S. Mohajerani et al., "Rapid formation of mono-dispersed hydroxyapatite nanorods with narrow-size distribution via microwave irradiation," Journal of the American Ceramic Society, vol. 91, no. 11, pp. 3580-3584, 2008.

[36] S. Duan and R. Wang, "Bimetallic nanostructures with magnetic and noble metals and their physicochemical applications," Progress in Natural Science: Materials International, vol. 23, no. 2, pp. 113-126, 2013.

[37] K. Lu, “The future of metals," Science, vol. 328, no. 5976, pp. 319320, 2010.

[38] C. N. R. Rao, G. U. Kulkarni, P. J. Thomas, and P. P. Edwards, "Metal nanoparticles and their assemblies," Chemical Society Reviews, vol. 29, no. 1, pp. 27-35, 2000.

[39] N. Toshima, "Recent progress in applications of ligandstabilized metal nanoclusters," Macromolecular Symposia, vol. 204, pp. 219-226, 2003.

[40] J. P. Wilcoxon and B. L. Abrams, "Synthesis, structure and properties of metal nanoclusters," Chemical Society Reviews, vol. 35, no. 11, pp. 1162-1194, 2006.

[41] E. Roduner, "Size matters: why nanomaterials are different," Chemical Society Reviews, vol. 35, no. 7, pp. 583-592, 2006.

[42] S. Xiao, W. Hu, W. Luo, Y. Wu, X. Li, and H. Deng, "Size effect on alloying ability and phase stability of immiscible bimetallic nanoparticles," European Physical Journal B, vol. 54, no. 4, pp. 479-484, 2006.

[43] S. Link, Z. L. Wang, and M. A. El-Sayed, "Alloy formation of gold-silver nanoparticles and the dependence of the plasmon absorption on their composition," Journal of Physical Chemistry $B$, vol. 103, no. 18, pp. 3529-3533, 1999.

[44] K. J. Major, C. De, and S. O. Obare, "Recent advances in the synthesis of plasmonic bimetallic nanoparticles," Plasmonics, vol. 4, no. 1, pp. 61-78, 2009.

[45] S. A. Chambers and Y. K. Yoo, "New materials for spintronics," MRS Bulletin, vol. 28, no. 10, pp. 706-710, 2003.

[46] D. Wang and Y. Li, "Bimetallic nanocrystals: liquid-phase synthesis and catalytic applications," Advanced Materials, vol. 23, no. 9, pp. 1044-1060, 2011.

[47] R. Sardar, A. M. Funston, P. Mulvaney, and R. W. Murray, "Gold nanoparticles: past, present, and future," Langmuir, vol. 25, no. 24, pp. 13840-13851, 2009.

[48] M. Haruta, N. Yamada, T. Kobayashi, and S. Iijima, "Gold catalysts prepared by coprecipitation for low-temperature oxidation of hydrogen and of carbon monoxide," Journal of Catalysis, vol. 115, no. 2, pp. 301-309, 1989.

[49] M. Valden, X. Lai, and D. W. Goodman, "Onset of catalytic activity of gold clusters on titania with the appearance of nonmetallic properties," Science, vol. 281, no. 5383, pp. 16471650, 1998.

[50] J. Zeng, Y. Zheng, M. Rycenga et al., "Controlling the shapes of silver nanocrystals with different capping agents," Journal of the American Chemical Society, vol. 132, no. 25, pp. 8552-8553, 2010.

[51] R. Sardar, C. A. Beasley, and R. W. Murray, "Interfacial ion transfers between a monolayer phase of cationic Au nanoparticles and contacting organic solvent," Journal of the American Chemical Society, vol. 132, no. 6, pp. 2058-2063, 2010.

[52] Z. Huo, C.-K. Tsung, W. Huango et al., "Self-organized ultrathin oxide nanocrystals," Nano Letters, vol. 9, no. 3, pp. 1260-1264, 2009.

[53] X. Huang, S. Tang, H. Zhang, Z. Zhou, and N. Zheng, "Controlled formation of concave tetrahedral/trigonal bipyramidal palladium nanocrystals," Journal of the American Chemical Society, vol. 131, no. 39, pp. 13916-13917, 2009.

[54] J. A. Rodriguez and D. W. Goodman, "The nature of the metalmetal bond in bimetallic surfaces," Science, vol. 257, no. 5072, pp. 897-903, 1992.

[55] J. Tanori, N. Duxin, C. Petit, I. Lisiecki, P. Veillet, and M. P. Pileni, "Synthesis of nanosize metallic and alloyed particles in ordered phases," Colloid \& Polymer Science, vol. 273, no. 9, pp. 886-892, 1995.

[56] Q. Ge, Y. Huang, F. Qiu, and S. Li, "Bifunctional catalysts for conversion of synthesis gas to dimethyl ether," Applied Catalysis A: General, vol. 167, no. 1, pp. 23-30, 1998.

[57] F. Massicot, R. Schneider, Y. Fort, S. Illy-Cherrey, and O. Tillement, "Synergistic effect in bimetallic Ni-Al clusters. Application to efficient catalytic reductive dehalogenation of polychlorinated arenes," Tetrahedron, vol. 56, no. 27, pp. 4765-4768, 2000.

[58] M. O. Nutt, J. B. Hughes, and M. S. Wong, "Designing Pdon-Au bimetallic nanoparticle catalysts for trichloroethene hydrodechlorination," Environmental Science and Technology, vol. 39, no. 5, pp. 1346-1353, 2005.

[59] R. Mu, Q. Fu, H. Xu et al., "Synergetic effect of surface and subsurface $\mathrm{Ni}$ species at $\mathrm{Pt}-\mathrm{Ni}$ bimetallic catalysts for $\mathrm{CO}$ oxidation," Journal of the American Chemical Society, vol. 133, no. 6, pp. 1978-1986, 2011.

[60] N. S. Sobal, U. Ebels, H. Möhwald, and M. Giersig, "Synthesis of core-shell PtCo nanocrystals," Journal of Physical Chemistry $B$, vol. 107, no. 30, pp. 7351-7354, 2003. 
[61] D. Kodama, K. Shinoda, K. Sato et al., "Chemical synthesis of sub-micrometer- to nanometer-sized magnetic FeCo dice," Advanced Materials, vol. 18, no. 23, pp. 3154-3159, 2006.

[62] C. Wang, S. Peng, L.-M. Lacroix, and S. Sun, "Synthesis of high magnetic moment CoFe nanoparticles via interfacial diffusion in core/shell structured Co/Fe nanoparticles," Nano Research, vol. 2, no. 5, pp. 380-385, 2009.

[63] O. M. Wilson, R. W. J. Scott, J. C. Garcia-Martinez, and R. M. Crooks, "Synthesis, characterization, and structure-selective extraction of 1-3-nm diameter AuAg dendrimer-encapsulated bimetallic nanoparticles," Journal of the American Chemical Society, vol. 127, no. 3, pp. 1015-1024, 2005.

[64] T. Som and B. Karmakar, "Core-shell Au-Ag nanoparticles in dielectric nanocomposites with plasmon-enhanced fluorescence: a new paradigm in antimony glasses," Nano Research, vol. 2, no. 8, pp. 607-616, 2009.

[65] Y. Kang, X. Ye, and C. B. Murray, "Size- and shape-selective synthesis of metal nanocrystals and nanowires using $\mathrm{CO}$ as a reducing agent," Angewandte Chemie, vol. 49, no. 35, pp. 61566159, 2010.

[66] Y. Kang and C. B. Murray, "Synthesis and electrocatalytic properties of cubic Mn-Pt nanocrystals (nanocubes)," Journal of the American Chemical Society, vol. 132, no. 22, pp. 7568-7569, 2010.

[67] X. Gu, L. Xu, F. Tian, and Y. Ding, "Au-Ag alloy nanoporous nanotubes," Nano Research, vol. 2, no. 5, pp. 386-393, 2009.

[68] Z. Liu, G. S. Jackson, and B. W. Eichhorn, "PtSn intermetallic, core-shell, and alloy nanoparticles as CO-tolerant electrocatalysts for $\mathrm{H}_{2}$ oxidation," Angewandte Chemie, vol. 49, no. 18, pp. 3173-3176, 2010.

[69] J. Xu, T. White, P. Li et al., "Biphasic Pd-Au alloy catalyst for lowtemperature CO oxidation," Journal of the American Chemical Society, vol. 132, no. 30, pp. 10398-10406, 2010.

[70] Y. Yoo, K. Seo, S. Han et al., "Steering epitaxial alignment of $\mathrm{Au}, \mathrm{Pd}$, and AuPd nanowire arrays by atom flux change," Nano Letters, vol. 10, no. 2, pp. 432-438, 2010.

[71] J.-M. Yan, X.-B. Zhang, T. Akita, M. Haruta, and Q. Xu, "One-step seeding growth of magnetically recyclable AU@Co core-shell nanoparticles: highly efficient catalyst for hydrolytic dehydrogenation of ammonia borane," Journal of the American Chemical Society, vol. 132, no. 15, pp. 5326-5327, 2010.

[72] Y. W. Lee, M. Kim, Y. Kim, S. W. Kang, J.-H. Lee, and S. W. Han, "Synthesis and electrocatalytic activity of Au-Pd alloy nanodendrites for ethanol oxidation," Journal of Physical Chemistry C, vol. 114, no. 17, pp. 7689-7693, 2010.

[73] J. Zhang, H. Yang, J. Fang, and S. Zou, "Synthesis and oxygen reduction activity of shape-controlled $\mathrm{Pt}_{3} \mathrm{Ni}$ nanopolyhedra," Nano Letters, vol. 10, no. 2, pp. 638-644, 2010.

[74] G. Krylova, N. M. Dimitrijevic, D. V. Talapin et al., "Probing the surface of transition-metal nanocrystals by chemiluminesence," Journal of the American Chemical Society, vol. 132, no. 26, pp. 9102-9110, 2010.

[75] R. Ferrando, J. Jellinek, and R. L. Johnston, "Nanoalloys: from theory to applications of alloy clusters and nanoparticles," Chemical Reviews, vol. 108, no. 3, pp. 845-910, 2008.

[76] D. Wang, T. Xie, Q. Peng, and Y. Li, "Ag, Ag2S, and Ag2Se nanocrystals: synthesis, assembly, and construction of mesoporous structures," Journal of the American Chemical Society, vol. 130, no. 12, pp. 4016-4022, 2008.

[77] T. K. Sau and A. L. Rogach, "Nonspherical noble metal nanoparticles: colloid-chemical synthesis and morphology control," Advanced Materials, vol. 22, no. 16, pp. 1781-1804, 2010.
[78] U. Banin, "Nanocrystals: tiny seeds make a big difference," Nature Materials, vol. 6, no. 9, pp. 625-626, 2007.

[79] H. Rui, R. Xing, Z. Xu, Y. Hou, S. Goo, and S. Sun, "Synthesis, functionalization, and biomedical applications of multifunctional magnetic nanoparticles," Advanced Materials, vol. 22, no. 25, pp. 2729-2742, 2010.

[80] T. Novet and D. C. Johnson, "New synthetic approach to extended solids: selective synthesis of iron suicides via the amorphous state," Journal of the American Chemical Society, vol. 113, no. 9, pp. 3398-3403, 1991.

[81] C. Suryanarayana, "Mechanical alloying and milling," Progress in Materials Science, vol. 46, no. 1-2, pp. 1-184, 2001.

[82] C. Xu, H. Wang, P. K. Shen, and S. P. Jiang, "Highly ordered Pd nanowire arrays as effective electrocatalysts for ethanol oxidation in direct alcohol fuel cells," Advanced Materials, vol. 19, no. 23, pp. 4256-4259, 2007.

[83] S. Sun, F. Jaouen, and J.-P. Dodelet, "Controlled growth of Pt nanowires on carbon nanospheres and their enhanced performance as electrocatalysts in PEM fuel cells," Advanced Materials, vol. 20, no. 20, pp. 3900-3904, 2008.

[84] C. Zhu, S. Guo, and S. Dong, "PdM ( $\mathrm{M}=\mathrm{Pt}, \mathrm{Au})$ bimetallic alloy nanowires with enhanced electrocatalytic activity for electrooxidation of small molecules," Advanced Materials, vol. 24, no. 17, pp. 2326-2331, 2012.

[85] S. Guo and S. Dong, "Metal nanomaterial-based self-assembly: development, electrochemical sensing and SERS applications," Journal of Materials Chemistry, vol. 21, no. 42, pp. 16704-16716, 2011.

[86] C. Koenigsmann, A. C. Santulli, K. Gong et al., "Enhanced electrocatalytic performance of processed, ultrathin, supported Pd-Pt core-shell nanowire catalysts for the oxygen reduction reaction," Journal of the American Chemical Society, vol. 133, no. 25, pp. 9783-9795, 2011.

[87] Q. Yuan, Z. Zhou, J. Zhuang, and X. Wang, "Pd-Pt random alloy nanocubes with tunable compositions and their enhanced electrocatalytic activities," Chemical Communications, vol. 46, no. 9, pp. 1491-1493, 2010.

[88] H. Zhang, M. Jin, and Y. Xia, "Enhancing the catalytic and electrocatalytic properties of Pt-based catalysts by forming bimetallic nanocrystals with Pd," Chemical Society Reviews, vol. 41, no. 24, pp. 8035-8049, 2012.

[89] B. Lim, J. Wang, P. H. C. Camargo, M. Jiang, M. J. Kim, and Y. Xia, "Facile synthesis of bimetallic nanoplates consisting of Pd Cores and Pt shells through seeded epitaxial growth," Nano Letters, vol. 8, no. 8, pp. 2535-2540, 2008.

[90] B. Lim, M. Jiang, P. H. C. Camargo et al., "Pd-Pt bimetallic nanodendrites with high activity for oxygen reduction," Science, vol. 324, no. 5932, pp. 1302-1305, 2009.

[91] B. Lim, M. Jiang, T. Yu, P. H. C. Camargo, and Y. Xia, "Nucleation and growth mechanisms for Pd-Pt bimetallic nanodendrites and their electrocatalytic properties," Nano Research, vol. 3, no. 2, pp. 69-80, 2010.

[92] S. Guo, S. Dong, and E. Wang, “Three-dimensional Pt-on-Pd bimetallic nanodendrites supported on graphene nanosheet: facile synthesis and used as an advanced nanoelectrocatalyst for methanol oxidation," ACS Nano, vol. 4, no. 1, pp. 547-555, 2010.

[93] V. Mazumder, M. Chi, K. L. More, and S. Sun, "Core/Shell $\mathrm{Pd} / \mathrm{FePt}$ nanoparticles as an active and durable catalyst for the oxygen reduction reaction," Journal of the American Chemical Society, vol. 132, no. 23, pp. 7848-7849, 2010. 
[94] H. Wang, R. Wang, H. Li, Q. Wang, J. Kang, and Z. Lei, "Facile synthesis of carbon-supported pseudo-core@shell PdCu@Pt nanoparticles for direct methanol fuel cells," International Journal of Hydrogen Energy, vol. 36, no. 1, pp. 839-848, 2011.

[95] L. Wang, Y. Nemoto, and Y. Yamauchi, "Direct synthesis of spatially-controlled Pt-on-Pd bimetallic nanodendrites with superior electrocatalytic activity," Journal of the American Chemical Society, vol. 133, no. 25, pp. 9674-9677, 2011.

[96] Y. Liu, M. Chi, V. Mazumder et al., "Composition-controlled synthesis of bimetallic PdPt nanoparticles and their electrooxidation of methanol," Chemistry of Materials, vol. 23, no. 18, pp. 4199-4203, 2011.

[97] N. V. Long, T. D. Hien, T. Asaka, M. Ohtaki, and M. Nogami, "Synthesis and characterization of Pt-Pd alloy and core-shell bimetallic nanoparticles for direct methanol fuel cells (DMFCs): enhanced electrocatalytic properties of wellshaped core-shell morphologies and nanostructures," International Journal of Hydrogen Energy, vol. 36, no. 14, pp. 8478-8491, 2011.

[98] H. Zhang, M. Jin, J. Wang et al., "Synthesis of Pd-Pt bimetallic nanocrystals with a concave structure through a bromideinduced galvanic replacement reaction," Journal of the American Chemical Society, vol. 133, no. 15, pp. 6078-6089, 2011.

[99] H. Zhang, M. Jin, H. Liu et al., "Facile synthesis of Pd-Pt Alloy nanocages and their enhanced performance for preferential oxidation of co in excess hydrogen," ACS Nano, vol. 5, no. 10, pp. 8212-8222, 2011.

[100] H. Wu, H. Li, Y. Zhai, X. Xu, and Y. Jin, "Facile synthesis of free-standing Pd-based nanomembranes with enhanced catalytic performance for methanol/ethanol oxidation," Advanced Materials, vol. 24, no. 12, pp. 1594-1597, 2012.

[101] Z. Huang, H. Zhou, F. Sun et al., "Facile self-assembly synthesis of PdPt bimetallic nanotubes with good performance for ethanol oxidation in an alkaline medium," Chemistry, vol. 19, no. 41, pp. 13720-13725, 2013.

[102] Z. Peng, J. Wu, and H. Yang, "Synthesis and oxygen reduction electrocatalytic property of platinum hollow and platinum-onsilver nanoparticles," Chemistry of Materials, vol. 22, no. 3, pp. 1098-1106, 2010.

[103] H. Kobayashi, M. Yamauchi, H. Kitagawa, Y. Kubota, K. Kato, and M. Takata, "Atomic-level Pd-Pt alloying and largely enhanced hydrogen-storage capacity in bimetallic nanoparticles reconstructed from core/shell structure by a process of hydrogen absorption/desorption," Journal of the American Chemical Society, vol. 132, no. 16, pp. 5576-5577, 2010.

[104] H. Zhang, Y. Yin, Y. Hu et al., "Pd@Pt core-shell nanostructures with controllable composition synthesized by a microwave method and their enhanced electrocatalytic activity toward oxygen reduction and methanol oxidation," Journal of Physical Chemistry C, vol. 114, no. 27, pp. 11861-11867, 2010.

[105] X. Bo, J. Bai, L. Yang, and L. Guo, "The nanocomposite of PtPd nanoparticles/onion-like mesoporous carbon vesicle for nonenzymatic amperometric sensing of glucose," Sensors and Actuators B: Chemical, vol. 157, no. 2, pp. 662-668, 2011.

[106] S. Cao, L. Zhang, Y. Chai, and R. Yuan, "Electrochemistry of cholesterol biosensor based on a novel Pt-Pd bimetallic nanoparticle decorated graphene catalyst," Talanta, vol. 109, pp. 167-172, 2013.

[107] Q. Zhang, J. Xie, Y. Yu, and J. Y. Lee, "Monodispersity control in the synthesis of monometallic and bimetallic quasi-spherical gold and silver nanoparticles," Nanoscale, vol. 2, no. 10, pp. 1962$1975,2010$.
[108] P. R. Selvakannan, A. Swami, D. Srisathiyanarayanan et al., "Synthesis of aqueous Au core-Ag shell nanoparticles using tyrosine as a $\mathrm{pH}$-dependent reducing agent and assembling phase-transferred silver nanoparticles at the air-water interface," Langmuir, vol. 20, no. 18, pp. 7825-7836, 2004.

[109] T. Sakai and P. Alexandridis, "Ag and $\mathrm{Au}$ monometallic and bimetallic colloids: morphogenesis in amphiphilic block copolymer solutions," Chemistry of Materials, vol. 18, no. 10, pp. 2577-2583, 2006.

[110] T. Sakai and P. Alexandridis, "Facile preparation of Ag-Au bimetallic nanonetworks," Materials Letters, vol. 60, no. 16, pp. 1983-1986, 2006.

[111] J. Chen, J. M. McLellan, A. Siekkinen, Y. Xiong, Z.-Y. Li, and Y. $\mathrm{Xia}$, "Facile synthesis of gold-silver nanocages with controllable pores on the surface," Journal of the American Chemical Society, vol. 128, no. 46, pp. 14776-14777, 2006.

[112] Y. W. Lee, M. Kim, Z. H. Kim, and S. W. Han, "One-step synthesis of Au@Pd core-shell nanooctahedron," Journal of the American Chemical Society, vol. 131, no. 47, pp. 17036-17037, 2009.

[113] X. Liu, A. Wang, X. Yang et al., "Synthesis of thermally stable and highly active bimetallic $\mathrm{Au}-\mathrm{Ag}$ nanoparticles on inert supports," Chemistry of Materials, vol. 21, no. 2, pp. 410-418, 2009.

[114] D. Philip, "Biosynthesis of $\mathrm{Au}, \mathrm{Ag}$ and $\mathrm{Au}-\mathrm{Ag}$ nanoparticles using edible mushroom extract," Spectrochimica Acta A: Molecular and Biomolecular Spectroscopy, vol. 73, no. 2, pp. 374-381, 2009.

[115] S. Xing, Y. Feng, Y. Y. Tay et al., "Reducing the symmetry of bimetallic Au@Ag nanoparticles by exploiting eccentric polymer shells," Journal of the American Chemical Society, vol. 132, no. 28, pp. 9537-9539, 2010.

[116] S. Tokonami, N. Morita, K. Takasaki, and N. Toshima, "Novel synthesis, structure, and oxidation catalysis of $\mathrm{Ag} / \mathrm{Au}$ bimetallic nanoparticles," Journal of Physical Chemistry C, vol. 114, no. 23, pp. 10336-10341, 2010.

[117] N. L. Netzer, C. Qiu, Y. Zhang et al., "Gold-silver bimetallic porous nanowires for surface-enhanced Raman scattering," Chemical Communications, vol. 47, no. 34, pp. 9606-9608, 2011.

[118] X. Hong, D. Wang, R. Yu et al., "Ultrathin Au-Ag bimetallic nanowires with Coulomb blockade effects," Chemical Communications, vol. 47, no. 18, pp. 5160-5162, 2011.

[119] B. Xia, F. He, and L. Li, "Preparation of bimetallic nanoparticles using a facile green synthesis method and their application," Langmuir, vol. 29, no. 15, pp. 4901-4907, 2013.

[120] K.-I. Okazaki, T. Kiyama, K. Hirahara, N. Tanaka, S. Kuwabata, and T. Torimoto, "Single-step synthesis of gold-silver alloy nanoparticles in ionic liquids by a sputter deposition technique," Chemical Communications, no. 6, pp. 691-693, 2008.

[121] T.-H. Tsai, S. Thiagarajan, and S.-M. Chen, "Ionic liquid assisted one step green synthesis of Au-Ag bimetallic nanoparticles," Journal of Applied Electrochemistry, vol. 40, no. 3, pp. 493-497, 2010.

[122] C. M. Gonzalez, Y. Liu, and J. C. Scaiano, "Photochemical strategies for the facile synthesis of gold-silver alloy and coreshell bimetallic nanoparticles," Journal of Physical Chemistry C, vol. 113, no. 27, pp. 11861-11867, 2009.

[123] L. Shang, L. Jin, S. Guo, J. Zhai, and S. Dong, "A facile and controllable strategy to synthesize Au-Ag alloy nanoparticles within polyelectrolyte multilayer nanoreactors upon thermal reduction," Langmuir, vol. 26, no. 9, pp. 6713-6719, 2010. 
[124] G. Zhang, Y. Kuang, J. Liu, Y. Cui, J. Chen, and H. Zhou, "Fabrication of Ag/Au bimetallic nanoparticles by UPD-redox replacement: application in the electrochemical reduction of benzyl chloride," Electrochemistry Communications, vol. 12, no. 9, pp. 1233-1236, 2010.

[125] P. H. C. Camargo, Y. Xiong, L. Ji, J. M. Zuo, and Y. Xia, "Facile synthesis of tadpole-like nanostructures consisting of Au heads and Pd tails," Journal of the American Chemical Society, vol. 129, no. 50, pp. 15452-15453, 2007.

[126] Y. W. Lee, N. H. Kim, K. Y. Lee, K. Kwon, M. Kim, and S. W. Han, "Synthesis and characterization of flower-shaped porous $\mathrm{Au}-\mathrm{Pd}$ alloy nanoparticles," Journal of Physical Chemistry C, vol. 112, no. 17, pp. 6717-6722, 2008.

[127] F. Ksar, L. Ramos, B. Keita, L. Nadjo, P. Beaunier, and H. Remita, "Bimetallic palladium-gold nanostructures: application in ethanol oxidation," Chemistry of Materials, vol. 21, no. 15, pp. 3677-3683, 2009.

[128] B. Lim, H. Kobayashi, T. Yu et al., "Synthesis of pd-au bimetallic nanocrystals via controlled overgrowth," Journal of the American Chemical Society, vol. 132, no. 8, pp. 2506-2507, 2010.

[129] V. Mazumder, M. Chi, K. L. More, and S. Sun, "Synthesis and characterization of multimetallic $\mathrm{Pd} / \mathrm{Au}$ and $\mathrm{Pd} / \mathrm{Au} / \mathrm{FePt}$ core/shell nanoparticles," Angewandte Chemie, vol. 49, no. 49, pp. 9368-9372, 2010.

[130] G. Zhan, J. Huang, M. Du, I. Abdul-Rauf, Y. Ma, and Q. Li, "Green synthesis of Au-Pd bimetallic nanoparticles: single-step bioreduction method with plant extract," Materials Letters, vol. 65, no. 19-20, pp. 2989-2991, 2011.

[131] H. Liu and Q. Yang, "Facile fabrication of nanoporous Au-Pd bimetallic foams with high catalytic activity for 2-nitrophenol reduction and SERS property," Journal of Materials Chemistry, vol. 21, no. 32, pp. 11961-11967, 2011.

[132] J. W. Hong, Y. W. Lee, M. Kim, S. W. Kang, and S. W. Han, "One-pot synthesis and electrocatalytic activity of octapodal Au-Pd nanoparticles," Chemical Communications, vol. 47, no. 9, pp. 2553-2555, 2011.

[133] S. Ge, F. Liu, W. Liu, M. Yan, X. Song, and J. Yu, "Colorimetric assay of K-562 cells based on folic acid-conjugated porous bimetallic Pd@Au nanoparticles for point-of-care testing," Chemical Communications, vol. 50, no. 4, pp. 475-477, 2013.

[134] S. Mandal, A. B. Mandale, and M. Sastry, "Keggin ion-mediated synthesis of aqueous phase-pure Au@Pd and Au@Pt core-shell nanoparticles," Journal of Materials Chemistry, vol. 14, no. 19, pp. 2868-2871, 2004.

[135] H. Kobayashi, M. Yamauchi, R. Ikeda, and H. Kitagawa, "Atomic-level Pd-Au alloying and controllable hydrogenabsorption properties in size-controlled nanoparticles synthesized by hydrogen reduction," Chemical Communications, no. 32, pp. 4806-4808, 2009.

[136] G. Zhang, H. Zhou, C. An, D. Liu, Z. Huang, and Y. Huang, "Bimetallic palladium-gold nanoparticles synthesized in ionic liquid microemulsion," Colloid and Polymer Science, vol. 290, no. 14, pp. 1435-1441, 2012.

[137] Y. He, N. Zhang, L. Zhang et al., "Fabrication of Au-Pd nanoparticles/graphene oxide and their excellent catalytic performance," Materials Research Bulletin, vol. 51, pp. 397-401, 2014.

[138] X. Chen, R. Tian, Q. Zhang, and C. Yao, "Target-induced electronic switch for ultrasensitive detection of $\mathrm{Pb}^{2+}$ based on three dimensionally ordered macroporous Au-Pd bimetallic electrode," Biosensors and Bioelectronics, vol. 53, pp. 90-98, 2014.
[139] W. He, X. Wu, J. Liu et al., "Pt-guided formation of Pt-Ag alloy nanoislands on Au nanorods and improved methanol electrooxidation," Journal of Physical Chemistry C, vol. 113, no. 24, pp. 10505-10510, 2009.

[140] N. R. Jana, L. Gearheart, and C. J. Murphy, "Seed-mediated growth approach for shape-controlled synthesis of spheroidal and rod-like gold nanoparticles using a surfactant template," Advanced Materials, vol. 13, no. 18, pp. 1389-1393.

[141] J. He, I. Ichinose, T. Kunitake, A. Nakao, Y. Shiraishi, and N. Toshima, "Facile fabrication of Ag-Pd bimetallic nanoparticles in ultrathin $\mathrm{TiO}_{2}$-gel films: nanoparticle morphology and catalytic activity," Journal of the American Chemical Society, vol. 125, no. 36, pp. 11034-11040, 2003.

[142] J. B. Liu, W. Dong, P. Zhan, S. Z. Wang, J. H. Zhang, and Z. L. Wang, "Synthesis of bimetallic nanoshells by an improved electroless plating method," Langmuir, vol. 21, no. 5, pp. 16831686, 2005.

[143] C.-L. Lee, Y.-C. Huang, and L.-C. Kuo, "High catalytic potential of $\mathrm{Ag} / \mathrm{Pd}$ nanoparticles from self-regulated reduction method on electroless Ni deposition," Electrochemistry Communications, vol. 8, no. 6, pp. 1021-1026, 2006.

[144] J. Gao, X. Ren, D. Chen, F. Tang, and J. Ren, "Bimetallic AgPt hollow nanoparticles: synthesis and tunable surface plasmon resonance," Scripta Materialia, vol. 57, no. 8, pp. 687-690, 2007.

[145] J. B. Xu, T. S. Zhao, and Z. X. Liang, "Synthesis of active platinum-silver alloy electrocatalyst toward the formic acid oxidation reaction," Journal of Physical Chemistry C, vol. 112, no. 44, pp. 17362-17367, 2008.

[146] W. He, X. Wu, J. Liu et al., "Design of AgM bimetallic alloy nanostructures $(\mathrm{M}=\mathrm{Au}, \mathrm{Pd}, \mathrm{Pt})$ with tunable morphology and peroxidase-like activity," Chemistry of Materials, vol. 22, no. 9, pp. 2988-2994, 2010.

[147] R. Sachan, S. Yadavali, N. Shirato et al., "Self-organized bimetallic Ag-Co nanoparticles with tunable localized surface plasmons showing high environmental stability and sensitivity," Nanotechnology, vol. 23, no. 27, Article ID 275604, 2012.

[148] I. B. Szymańska, "Influence of the gas phase composition on the properties of bimetallic Ag/Cu nanomaterials obtained via chemical vapor deposition," Polyhedron, vol. 65, pp. 82-88, 2013.

[149] Q. Liu, Z. Yan, N. L. Henderson et al., "Synthesis of CuPt nanorod catalysts with tunable lengths," Journal of the American Chemical Society, vol. 131, no. 16, pp. 5720-5721, 2009.

[150] A. Ahniyaz, Y. Sakamoto, and L. Bergström, "Magnetic fieldinduced assembly of oriented superlattices from maghemite nanocubes," Proceedings of the National Academy of Sciences of the United States of America, vol. 104, no. 45, pp. 17570-17574, 2007.

[151] M. Chen, J. Kim, J. P. Liu, H. Fan, and S. Sun, "Synthesis of FePt nanocubes and their oriented self-assembly," Journal of the American Chemical Society, vol. 128, no. 22, pp. 7132-7133, 2006.

[152] T. Ming, X. Kou, H. Chen et al., "Ordered gold nanostructure assemblies formed by droplet evaporation," Angewandte Chemie, vol. 120, no. 50, pp. 9831-9836, 2008.

[153] Y. Liu and A. R. Hight Walker, "Monodisperse gold-copper bimetallic nanocubes: facile one-step synthesis with controllable size and composition," Angewandte Chemie, vol. 49, no. 38, pp. 6781-6785, 2010.

[154] V. Mazumder, M. Chi, M. N. Mankin et al., "A facile synthesis of $\operatorname{MPd}(\mathrm{M}=\mathrm{Co}, \mathrm{Cu})$ nanoparticles and their catalysis for formic acid oxidation," Nano Letters, vol. 12, no. 2, pp. 1102-1106, 2012. 
[155] F. Yu and W. Zhou, "Alloying and dealloying of CuPt bimetallic nanocrystals," Progress in Natural Science: Materials International, vol. 23, no. 3, pp. 331-337, 2013.

[156] L. Su, S. Shrestha, Z. Zhang, W. Mustain, and Y. Lei, "Platinumcopper nanotube electrocatalyst with enhanced activity and durability for oxygen reduction reactions," Journal of Materials Chemistry A, vol. 1, no. 39, pp. 12293-12301, 2013.

[157] F. Xiao, F. Zhao, D. Mei, Z. Mo, and B. Zeng, "Nonenzymatic glucose sensor based on ultrasonic-electrodeposition of bimetallic PtM ( $\mathrm{M}=\mathrm{Ru}, \mathrm{Pd}$ and $\mathrm{Au})$ nanoparticles on carbon nanotubes-ionic liquid composite film," Biosensors and Bioelectronics, vol. 24, no. 12, pp. 3481-3486, 2009.

[158] Q. Wu, Y. Li, H. Xian, C. Xu, L. Wang, and Z. Chen, "Ultralow Pt-loading bimetallic nanoflowers: fabrication and sensing applications," Nanotechnology, vol. 24, no. 2, Article ID 025501, 2013.

[159] S. Alayoglu, A. U. Nilekar, M. Mavrikakis, and B. Eichhorn, "RuPt core-shell nanoparticles for preferential oxidation of carbon monoxide in hydrogen," Nature Materials, vol. 7, no. 4, pp. 333$338,2008$.

[160] S. Guo and S. Sun, "FePt nanoparticles assembled on graphene as enhanced catalyst for oxygen reduction reaction," Journal of the American Chemical Society, vol. 134, no. 5, pp. 2492-2495, 2012.

[161] L. Zheng, L. Xiong, J. Sun, J. Li, S. Yang, and J. Xia, "Capping agent free synthesis of PtSn bimetallic nanoparticles with enhanced electrocatalytic activity and lifetime over methanol oxidation," Catalysis Communications, vol. 9, no. 5, pp. 624-629, 2008.

[162] J. Wang, R. M. Asmussen, B. Adams, D. F. Thomas, and A. Chen, "Facile synthesis and electrochemical properties of intermetallic PtPb nanodendrites," Chemistry of Materials, vol. 21, no. 8, pp. 1716-1724, 2009.

[163] Y. Li, P. Zhou, Z. Dai, Z. Hu, P. Sun, and J. Bao, "A facile synthesis of PdCo bimetallic hollow nanospheres and their application to Sonogashira reaction in aqueous media," New Journal of Chemistry, vol. 30, no. 6, pp. 832-837, 2006.

[164] D. Wang, H. L. Xin, H. Wang et al., "Facile synthesis of carbonsupported Pd-Co core-shell nanoparticles as oxygen reduction electrocatalysts and their enhanced activity and stability with monolayer Pt decoration," Chemistry of Materials, vol. 24, no. 12, pp. 2274-2281, 2012.

[165] X. Caixia, Z. Yan, X. Liqiang, B. Xiufang, M. Houyi, and D. Yi, "Nanotubular mesoporous $\mathrm{PdCu}$ bimetallic electrocatalysts toward oxygen reduction reaction," Chemistry of Materials, vol. 21, no. 14, pp. 3110-3116, 2009.

[166] L. Han, C. Zhu, L. Wang, and S. Dong, "Facile synthesis of chain-like $\mathrm{CoCu}$ bimetallic nanomaterials and their catalytic properties," Catalysis Science and Technology, vol. 3, no. 6, pp. 1501-1504, 2013.

[167] G. Chen, D. Xia, Z. Nie et al., "Facile synthesis of Co-Pt hollow sphere electrocatalyst," Chemistry of Materials, vol. 19, no. 7, pp. 1840-1844, 2007.

[168] Y. Vasquez, A. K. Sra, and R. E. Schaak, "One-pot synthesis of hollow superparamagnetic CoPt nanospheres," Journal of the American Chemical Society, vol. 127, no. 36, pp. 12504-12505, 2005. 

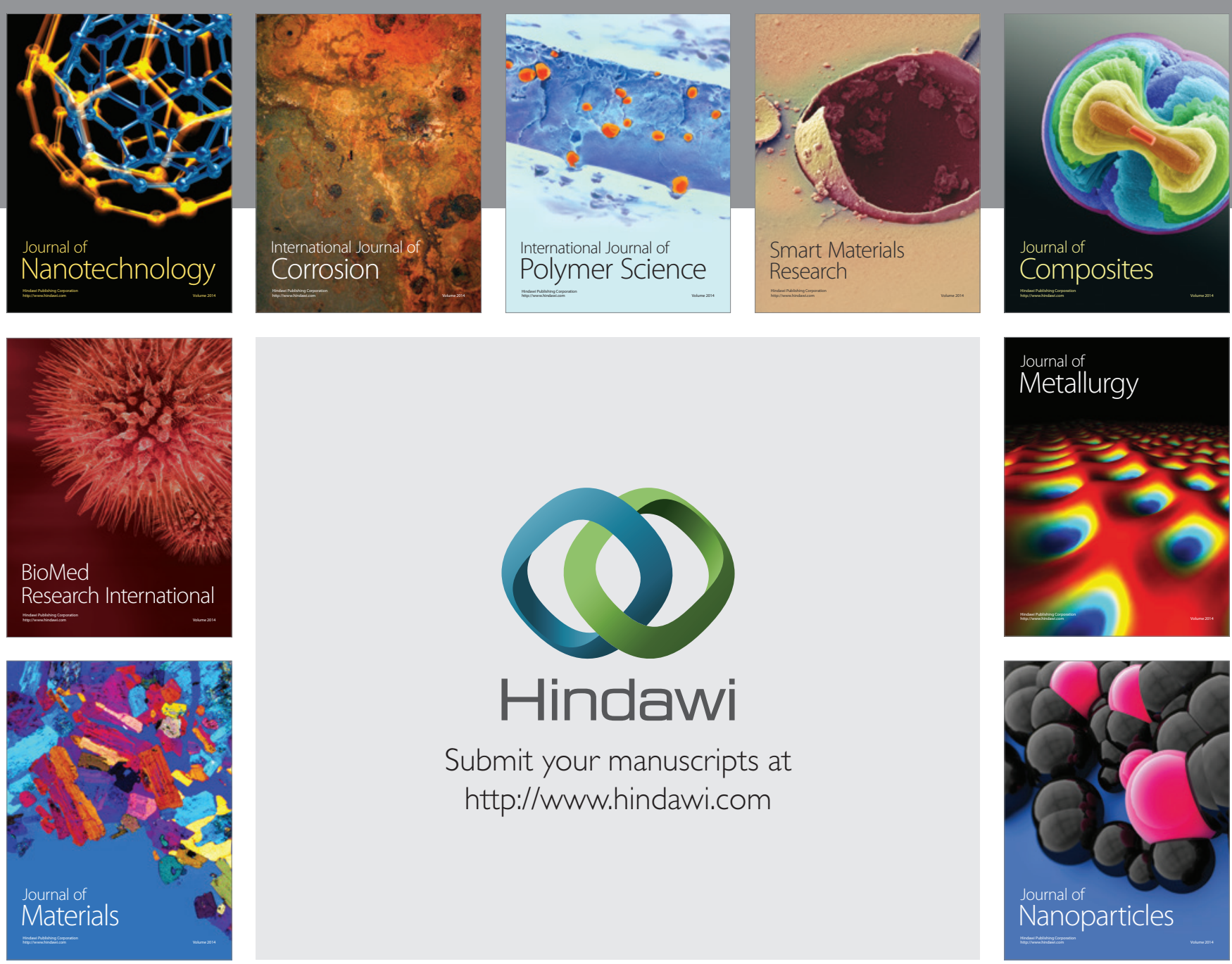

Submit your manuscripts at http://www.hindawi.com
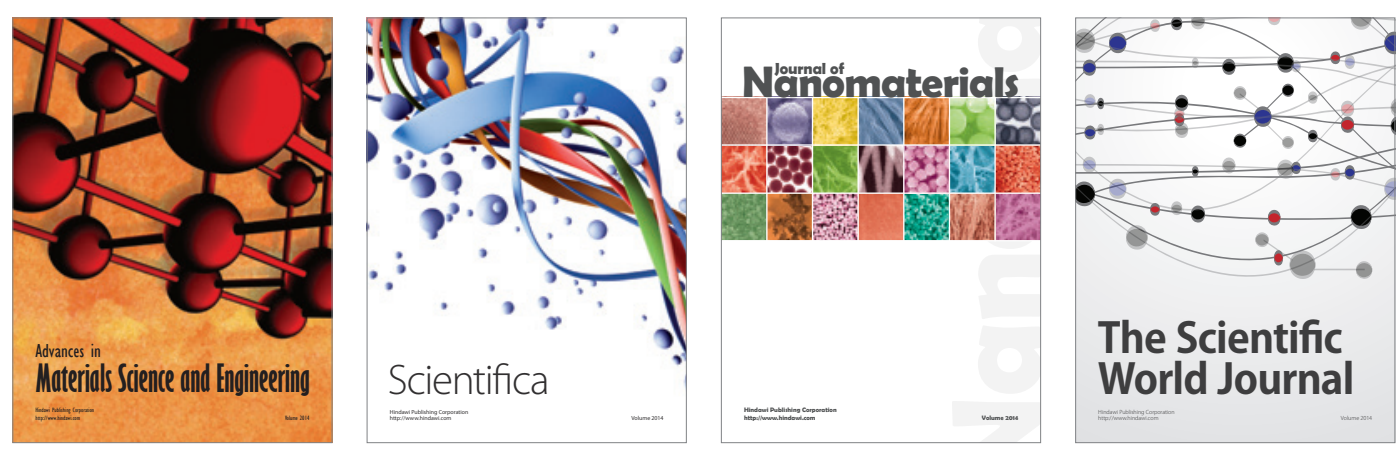

\section{The Scientific World Journal}
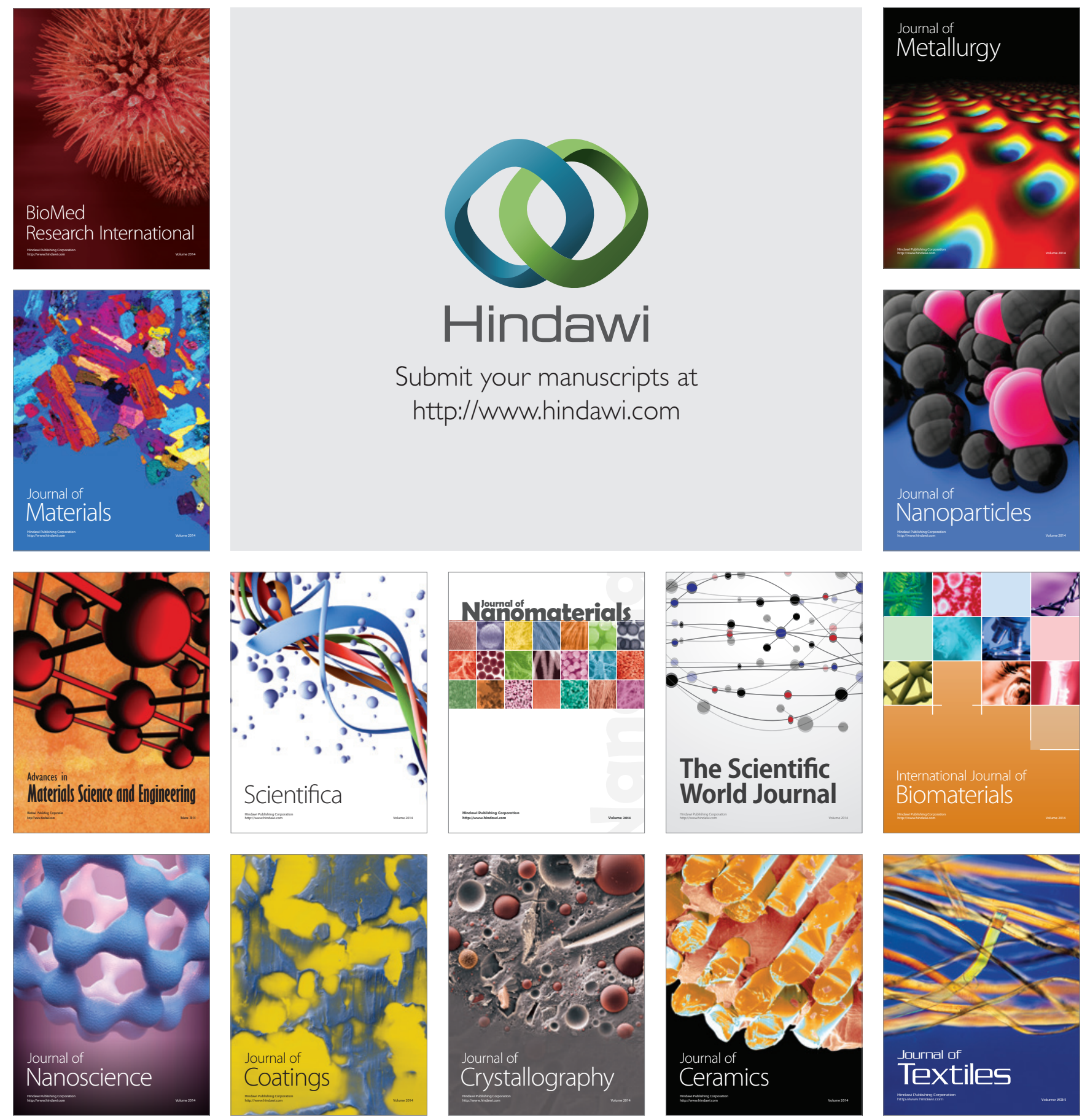